\title{
Design strategy for $\mathrm{Ag}(\mathrm{I})$-based thermally activated delayed fluorescence reaching an efficiency breakthrough
}

\author{
Marsel Z. Shafikov ${ }^{\dagger \star}$, Alfiya F. Suleymanova ${ }^{\dagger \S}$, Rafał Czerwieniec ${ }^{\dagger *}$, and Hartmut Yersin ${ }^{\dagger *}$ \\ † Institut für Physikalische und Theoretische Chemie, Universität Regensburg, \\ Universitätsstrasse 31, D-93053 Regensburg, Germany \\ ‡ Ural Federal University, Mira 19, Ekaterinburg, 620002, Russia \\ $\S$ I. Postovsky Institute of Organic Synthesis, Ekaterinburg, 620041, Russia.
}

Chem. Mater., 2017, 29 (4), pp 1708-1715

DOI: $10.1021 /$ acs.chemmater.6b05175

This work was supported in the framework of Marie Skłodowska-Curie Research and Innovation Staff Exchange (RISE) program

Project Number: 645628

Project Acronym: METCOPH

Project title: Metallocomplexes of macrocyclic compounds for photonic devices 


\title{
Design strategy for $\mathrm{Ag}(\mathrm{I})$-based thermally activated delayed fluorescence reaching an efficiency breakthrough
}

\author{
Marsel Z. Shafikov ${ }^{\dagger \star}$, Alfiya F. Suleymanova ${ }^{\dagger \S}$, Rafał Czerwieniec ${ }^{\dagger *}$, and Hartmut Yersin ${ }^{\dagger *}$ \\ † Institut für Physikalische und Theoretische Chemie, Universität Regensburg, \\ Universitätsstrasse 31, D-93053 Regensburg, Germany \\ ‡ Ural Federal University, Mira 19, Ekaterinburg, 620002, Russia \\ $\S$ I. Postovsky Institute of Organic Synthesis, Ekaterinburg, 620041, Russia.
}

\section{Abstract}

A design strategy is presented for the development of $\mathrm{Ag}(\mathrm{I})$-based materials for thermally activated delayed fluorescence (TADF). Although $\mathrm{Ag}(\mathrm{I})$ complexes usually do not show TADF, the designed material, $A g(d b p)\left(P_{2}-n C B\right)$ (with dbp = 2,9-di- $n$-butyl1,10-phenanthroline and $\mathrm{P}_{2}-\mathrm{nCB}=$ nido-carborane-bis-(diphenylphosphine)), shows a TADF efficiency breakthrough exhibiting an emission decay time of $\mathrm{T}(\mathrm{TADF})=1.4 \mu \mathrm{s}$ at a quantum yield of $\Phi_{P L}=100 \%$. This is a consequence of three optimized parameters: (i) The strongly electron-donating negatively charged $\mathrm{P}_{2}-\mathrm{nCB}$ ligand destabilizes the 4dorbitals and leads to low lying charge (CT) states of MLL'CT character, with L and L' being the two different ligands, thus, giving a small energy separation between the lowest singlet $S_{1}$ and triplet $T_{1}$ state of $\Delta E\left(S_{1}-T_{1}\right)=650 \mathrm{~cm}^{-1}$ (80 meV). (ii) The allowedness of the $S_{1} \rightarrow S_{0}$ transition is more than one order of magnitude higher than found for other TADF metal complexes, as shown experimentally and by TD-DFT calculations. Both parameters favor short TADF decay time. (iii) The high quantum efficiency is dominantly related to the rigid molecular structure of $A g(d b p)\left(P_{2}-n C B\right)$, resulting from the design strategy of introducing $n$-butyl substitutions at the 2,9positions of phenanthroline which sterically interact with the phenyl groups of the $\mathrm{P}_{2-}$ $\mathrm{nCB}$ ligand. In particular, the shortest TADF decay time of $\mathrm{T}(\mathrm{TADF})=1.4 \mu \mathrm{s}$ at $\Phi_{\mathrm{PL}}=$ $100 \%$ reported so far suggests the use of this outstanding material for OLEDs. 
Importantly, the emission of $\mathrm{Ag}(\mathrm{dbp})\left(\mathrm{P}_{2}-\mathrm{nCB}\right)$ is not subject to concentration quenching. Therefore, it may be applied even as a $100 \%$ emission layer.

\section{Introduction}

Fundamental research focusing on photophysical and chemical properties of organotransition metal complexes is strongly stimulated by potential applications, in particular, in the field of electro-luminescent devices, such as emitters for OLEDs ${ }^{1-15}$ or LEECs. ${ }^{7,16-}$ ${ }^{19}$ For the emitters, it is crucial that all generated singlet and triplet excitons ${ }^{20}$ are harvested and transferred into light. This can be achieved by two different mechanisms: (i) Complexes that exhibit high spin-orbit-coupling (SOC) with respect to the lowest excited triplet state $T_{1}$, representing triplet emitters, allow to harvest all excitons in the lowest triplet state. ${ }^{21-23}$ (ii) Compounds that show thermally activated delayed fluorescence (TADF) harvest also all excitons, but the emission occurs essentially via the thermally activated singlet state $\mathrm{S}_{1}{ }^{24-28}$

Development of TADF compounds is currently under heavy research, since such materials can be realized with low-cost and environmentally friendly $\mathrm{Cu}(\mathrm{l})$ complexes ${ }^{9,24,25,29-44}$ as well as with purely organic molecules. ${ }^{26,45,46}$ For organotransition metal compounds, the occurrence of TADF is crucially related to metal-toligand charge transfer (MLCT) states having frontier orbitals, HOMO and LUMO, that are spatially well separated. This leads to a small exchange interaction ${ }^{47,48}$ between the involved electrons and hence, to a small splitting $\Delta \mathrm{E}\left(\mathrm{S}_{1}-\mathrm{T}_{1}\right)$ between the lowest excited singlet state $S_{1}$ and triplet state $T_{1}$. A small $\Delta E\left(S_{1}-T_{1}\right)$ value is a necessary condition for obtaining a short (radiative) TADF decay time, being important for minimizing roll-off effects and stability problems in OLEDs. Additionally, the allowedness of the transition from the $S_{1}$ state to the ground state $\left(S_{0}\right), S_{1} \rightarrow S_{0}$, that is thermally activated from the lower lying triplet state plays a crucial role. However, basic quantum chemical considerations suggest that the corresponding rate $\mathrm{k}\left(\mathrm{S}_{1} \rightarrow \mathrm{S}_{0}\right)$ and $\Delta \mathrm{E}\left(\mathrm{S}_{1}-\mathrm{T}_{1}\right)$ are 
correlated. Small splitting $\Delta \mathrm{E}\left(\mathrm{S}_{1}-\mathrm{T}_{1}\right)$ requires that the exchange interaction between the unpaired electrons is small. For this, small overlap of HOMO and LUMO is advantageous. At the same time, small HOMO-LUMO overlap leads to a small oscillator strength of the $S_{1} \rightarrow S_{0}$ transition, and thus, to small $k\left(S_{1} \rightarrow S_{0}\right)$ and long fluorescence decay time. Indeed, experimental studies on $\mathrm{Cu}(\mathrm{I})$ complexes showing TADF reveal that such a correlation exists for a large number of compounds. ${ }^{34}$ Thus, engineering of TADF materials with shorter TADF decay times is a challenge. For instance, TADF decay times of less than a few $\mu$ s have not been reported so far29,32,36,39,49 In particular, there are no reports on (radiative) decay times shorter than 3 HS. ${ }^{34,49,50}$

In this investigation, we focus on a new $\mathrm{Ag}(\mathrm{I})$ complex that opens a breakthrough in designing a TADF material with a significantly shorter radiative TADF decay time. In contrast to $\mathrm{Cu}(\mathrm{I})$ based compounds, reports on $\mathrm{Ag}(\mathrm{I})$ based TADF materials are scarce. ${ }^{37,50,51}$ This is a consequence of the higher oxidation potential of the $\mathrm{Ag}^{+}$ion compared to the $\mathrm{Cu}^{+}$ion. ${ }^{52}$ Accordingly, the $4 \mathrm{~d}$-orbitals of $\mathrm{Ag}(\mathrm{I})$ complexes mostly lie energetically below ligand-centered (LC) orbitals. This leads to low-lying states of ${ }^{3} \mathrm{LC}$ character. ${ }^{53-56}$ Therefore, $\mathrm{Ag}(\mathrm{I})$ complexes often do not show TADF, but long-lived phosphorescence and sometimes even slow intersystem crossing (ISC) resulting in dual emission. ${ }^{55}$ Obviously, designing $A g(I)$ complexes that exhibit efficient and shortlived TADF represents an optimization challenge. For this aim, it is required to destabilize the energetically deep-lying $4 d$-orbitals by an organic ligand with good electron-donating properties. Accordingly, we choose a silver complex containing a chelating nido-carborane-bis-(diphenylphosphine) $\left(\mathrm{P}_{2}-\mathrm{nCB}\right)$ ligand $^{57}$ (structure shown in Scheme 1). The phosphine coordination induces substantial electron-donating character, which is further strongly enhanced by the negative charge of the nidocarborane moiety. In combination with the chromophoric 2,9-di- $n$-butyl-1,10- 
phenanthroline (dbp) ligand, we obtain the neutral $\mathrm{Ag}(\mathrm{dbp})\left(\mathrm{P}_{2}-\mathrm{nCB}\right)$ complex. Moreover, this compound is relatively rigid due to the rigid nido-carborane cage and, in particular, the sterically demanding 2,9-di- $n$-butyl substitutions at the phenanthroline ligand. This allows us to expect high emission quantum yield. ${ }^{31}$ Here we present the synthesis of the complex, characterize it by TD-DFT calculations and by detailed photophysical measurements investigating properties over a wide temperature range $(20 \mathrm{~K} \leq \mathrm{T} \leq 300 \mathrm{~K})$. In particular, it will be shown that the resulting $A g(d b p)\left(P_{2}-n C B\right)$ complex exhibits $100 \%$ emission quantum yield and an extraordinarily short radiative TADF decay time, being significantly shorter than reported for any other TADF material so far.

\section{Synthesis and molecular structure}

$\mathrm{Ag}(\mathrm{dbp})\left(\mathrm{P}_{2}-\mathrm{nCB}\right)$ was obtained by reacting equimolar amounts of silver hexafluorophosphate $\left(\mathrm{AgPF}_{6}\right)$, ortho-carborane-bis-(diphenylphosphine) $\left(\mathrm{P}_{2}-\mathrm{oCB}\right),{ }^{58}$ and 2,9-di- $n$-butyl-1,10-phennanthroline (dbp) in refluxing ethanol, in analogy to literature procedures ${ }^{57,59,60}$ (Scheme 1). Under these reaction conditions, orthocarborane of the cationic $\mathrm{Ag}(\mathrm{dbp})\left(\mathrm{P}_{2}-\mathrm{oCB}\right)^{+}$complex (not isolated) undergoes partial deboronation leading to the respective nido-carborane (nCB) anion, ${ }^{59}$ thus affording the neutral $\mathrm{Ag}(\mathrm{dbp})\left(\mathrm{P}_{2}-\mathrm{nCB}\right)$ complex. Synthetic procedure and structural characterization of $\mathrm{Ag}(\mathrm{dbp})\left(\mathrm{P}_{2}-\mathrm{nCB}\right)$ are given in the $\mathrm{ESI}$.

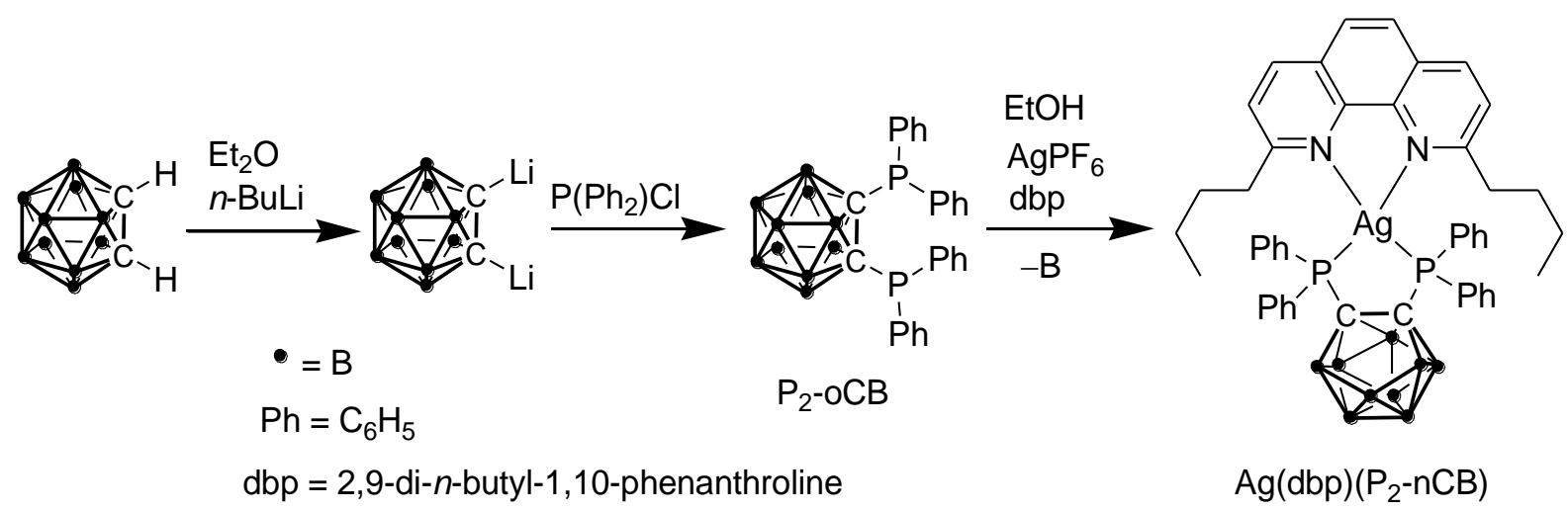

Scheme 1. Synthetic route to complex $A g(d b p)\left(P_{2}-n C B\right)$ 
X-ray single crystal diffraction study reveals the $\mathrm{Ag}(\mathrm{dbp})\left(\mathrm{P}_{2}-\mathrm{nCB}\right)$ molecule (Figure 1) in which the silver ion is chelated by the two ligands, dbp and $\mathrm{P}_{2}-\mathrm{nCB}$, in a distorted tetrahedral coordination. The mean bond lengths to the metal center P-Ag and N-Ag of $2.45 \AA$ and $2.32 \AA$, respectively, are unremarkable compared to other silver complexes $^{52,54,57,61,62}$ and are larger than in the analogous $\mathrm{Cu}(\mathrm{I})$ complexes due to the larger ion size of $\mathrm{Ag}^{+}$as compared to $\mathrm{Cu}^{+}$. The bite angles $\mathrm{P}-\mathrm{Ag}-\mathrm{P}$ and $\mathrm{N}-\mathrm{Ag}-\mathrm{N}$ of $86^{\circ}$ and $73^{\circ}$, respectively, are smaller than in analogous $\mathrm{Cu}(\mathrm{I})$ complexes. ${ }^{63}$ Voids between the phenyl groups of $\mathrm{P}_{2}$-nCB are partly occupied by the $n$-butyl chains of dbp. Owing to such steric effects, the arrangement of the ligand side groups is expected to rigidify the structure and thus, to restrain excited-state geometry distortions. ${ }^{64-70}$

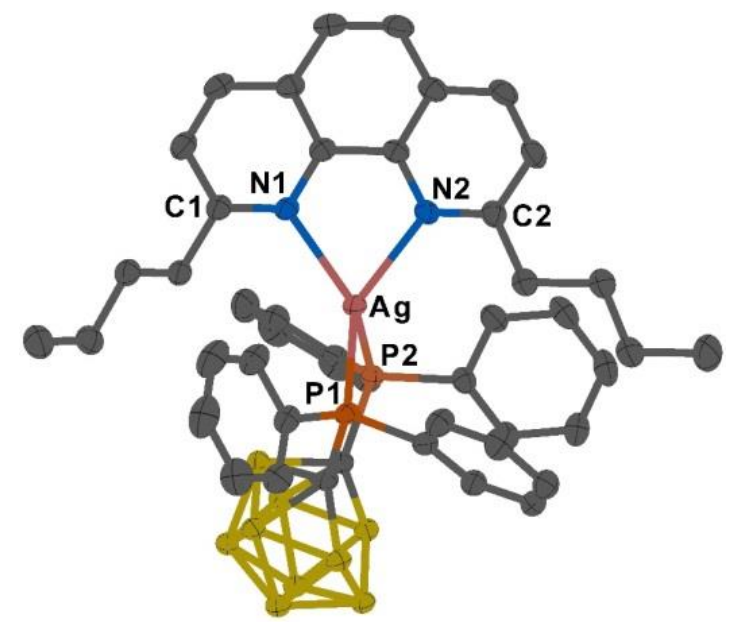

Figure 1. Chemical structure and perspective view (OLEX-2 ${ }^{71}$ plot with $50 \%$ probability thermal ellipsoids) of $\mathrm{Ag}(\mathrm{dbp})\left(\mathrm{P}_{2}-\mathrm{nCB}\right)$. Hydrogen atoms are omitted for clarity. For further data see the ESI.

\section{Theoretical calculations based on density functional theory (DFT) and time dependent DFT (TD-DFT) methods}

By use of DFT and TD-DFT calculations, we can obtain an insight into the electronic structure of $\mathrm{Ag}(\mathrm{dbp})\left(\mathrm{P}_{2}-\mathrm{nCB}\right)$. The calculations were carried out at the $\mathrm{M06}^{72} / \mathrm{def}_{2} \mathrm{SVP}^{73}$ level of theory for geometry optimizations and at the M062X72/def2SVP level for timedependent calculations (See the ESI for details). The optimized geometry of the ground 
sate $\left(S_{0}\right)$ is found to be in a good agreement with the experimental X-Ray geometry (Table $\mathrm{S} 1$ in the ESI). Calculations performed for both geometries, $\mathrm{S}_{0}$ and $\mathrm{T}_{1}$, reveal that the lowest electronic transitions, corresponding to states $S_{1}$ and $T_{1}$, involve electron density shifts from the metal, the phosphorus atoms, and the nido-carboranyl anion of the $\mathrm{P}_{2}$-nCB ligand to the phenanthroline core of the $\mathrm{dbp}$ ligand. This charge transfer results in a flattening distortion of the pseudo-tetrahedral ground state geometry as frequently described for $\mathrm{Cu}(\mathrm{I})$ complexes. ${ }^{64-70,74,75}$ Since the orbital origins of the states $T_{1}$ and $S_{1}$ are similar from the perspective of the ground state and mainly emission properties are discussed, we focus on the $T_{1}$ state geometry. In this geometry, the $\mathrm{S}_{0} \rightarrow \mathrm{S}_{1}$ excitation is dominated by the $\mathrm{HOMO} \rightarrow$ LUMO transition (92\%) perturbed by $\mathrm{HOMO}-1 \rightarrow$ LUMO character (4\%). (Figure 2 and Table S2 in the ESI) The HOMO is essentially composed of the metal (13\%) and phosphorus orbitals (47\%) (engaged in bonding to $\mathrm{Ag}$ ), while the LUMO represents a $\pi^{*}$ orbital of the dbp ligand (Figure 2 and Table S3 in the ESI). The $\mathrm{T}_{1}$ state is derived from almost the same one-electron excitations as the state $S_{1}$. Thus, the theoretical predictions allow us to assign the two lowest excited states as ${ }^{1,3}(\mathrm{MLL} C T)$ states, wherein $L$ and $L^{\prime}$ represent $P_{2}-n C B$ and $\mathrm{dbp}$, respectively. The calculated energy separation $\Delta \mathrm{E}\left(\mathrm{S}_{1}-\mathrm{T}_{1}\right)$, obtained as the difference of vertical excitation energies amounts to $0.15 \mathrm{eV}\left(\approx 1200 \mathrm{~cm}^{-1}\right)$ and thus is somewhat larger than the experimentally determined activation energy (Section 4). 


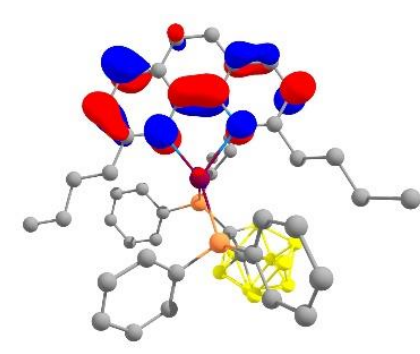

LUMO

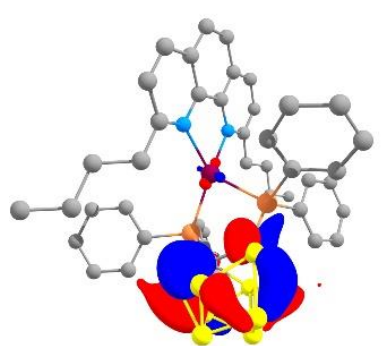

HOMO-1

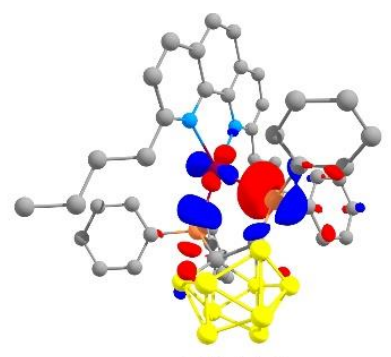

HOMO

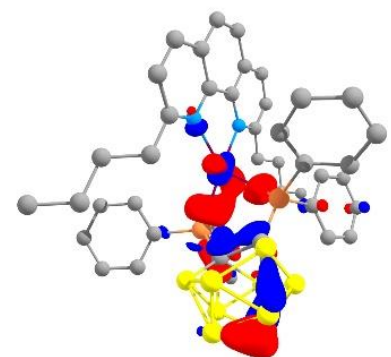

HOMO-2

Figure 2. Iso-surface contour plots (iso-value $=0.05)$ of frontier orbitals of $\mathrm{Ag}(\mathrm{dbp})\left(\mathrm{P}_{2}\right.$ $\mathrm{nCB}$ ), calculated at the M062X/Def2-SVP level of theory in the $\mathrm{T}_{1}$ excited state geometry. Hydrogen atoms are omitted for clarity. For further data see the ESI.

The calculations performed for the triplet state optimized geometry reveal further that the $S_{2}$ and $S_{3}$ states result mainly from the HOMO $\rightarrow$ LUMO+1 and HOMO-1 $\rightarrow$ LUMO transitions, respectively. Since $S_{2}$ carries the same type of metal $4 d$ character as $T_{1}$ (and as $S_{1}$ ) and since $S_{3}$ is largely of ligand-to-ligand charge transfer character with no significant contributions from the metal, spin-orbit admixtures of these states $\left(\mathrm{S}_{2}\right.$ and $\left.S_{3}\right)$ to the $T_{1}$ state are expected to be small. ${ }^{76-78}$ The nearest singlet state with metal $4 d$ contribution different from that in the $T_{1}$ state is $S_{4}$ (largely resulting from HOMO-2 $\rightarrow$ LUMO). It lies $1.57 \mathrm{eV}$ above the $\mathrm{T}_{1}$ level. For such a large energy difference, SOC is expected to be very small. (Compare refs. ${ }^{34,49,76-78}$ ) Thus, a very long phosphorescence decay time is expected to occur. This was experimentally observed, as shown in Section 4.

Importantly, the calculations predict a relatively high oscillator strength for the $S_{0} \rightarrow S_{1}$ transition of $f=0.0536$ (Table $\mathrm{S} 1$ in the ESI). For comparison, the $f$ values for chargetransfer transitions of $\mathrm{Cu}(\mathrm{l})$ complexes are usually more than one order of magnitude 
smaller. ${ }^{42,49}$ Indeed, the high allowedness of the $S_{0} \leftrightarrow S_{1}$ transition correlates well with the very high fluorescence rate as determined experimentally (Section 4).

\section{Photophysical characterization of $\mathrm{Ag}(\mathrm{dbp})\left(\mathrm{P}_{2}-\mathrm{nCB}\right)$}

\subsection{Spectroscopic introduction}

In Figure 3, we present a spectroscopic introduction to properties of $A g(d b p)\left(P_{2}-n C B\right)$. The absorption spectrum shows strong absorption bands in the UV region with maxima at $232 \mathrm{~nm}\left(57100 \mathrm{M}^{-1} \cdot \mathrm{cm}^{-1}\right)$ and $273 \mathrm{~nm}\left(37700 \mathrm{M}^{-1} \cdot \mathrm{cm}^{-1}\right)$ and a weaker band centered at $385 \mathrm{~nm}\left(2100 \mathrm{M}^{-1} \cdot \mathrm{cm}^{-1}\right)$. The short wavelength transitions are dominated by $\pi-\pi^{*}$ transitions within the $\mathrm{dbp}$ and $\mathrm{P}_{2}$-nCB ligands, while the long wavelength absorption is assigned, in analogy to mixed-ligand phenanthroline- $\mathrm{Cu}(\mathrm{I})$ complexes, ${ }^{36,63,79-84}$ to transitions with distinct charge transfer (CT) character. TD-DFT calculations predict a MLL'CT type of transition (Section 3).

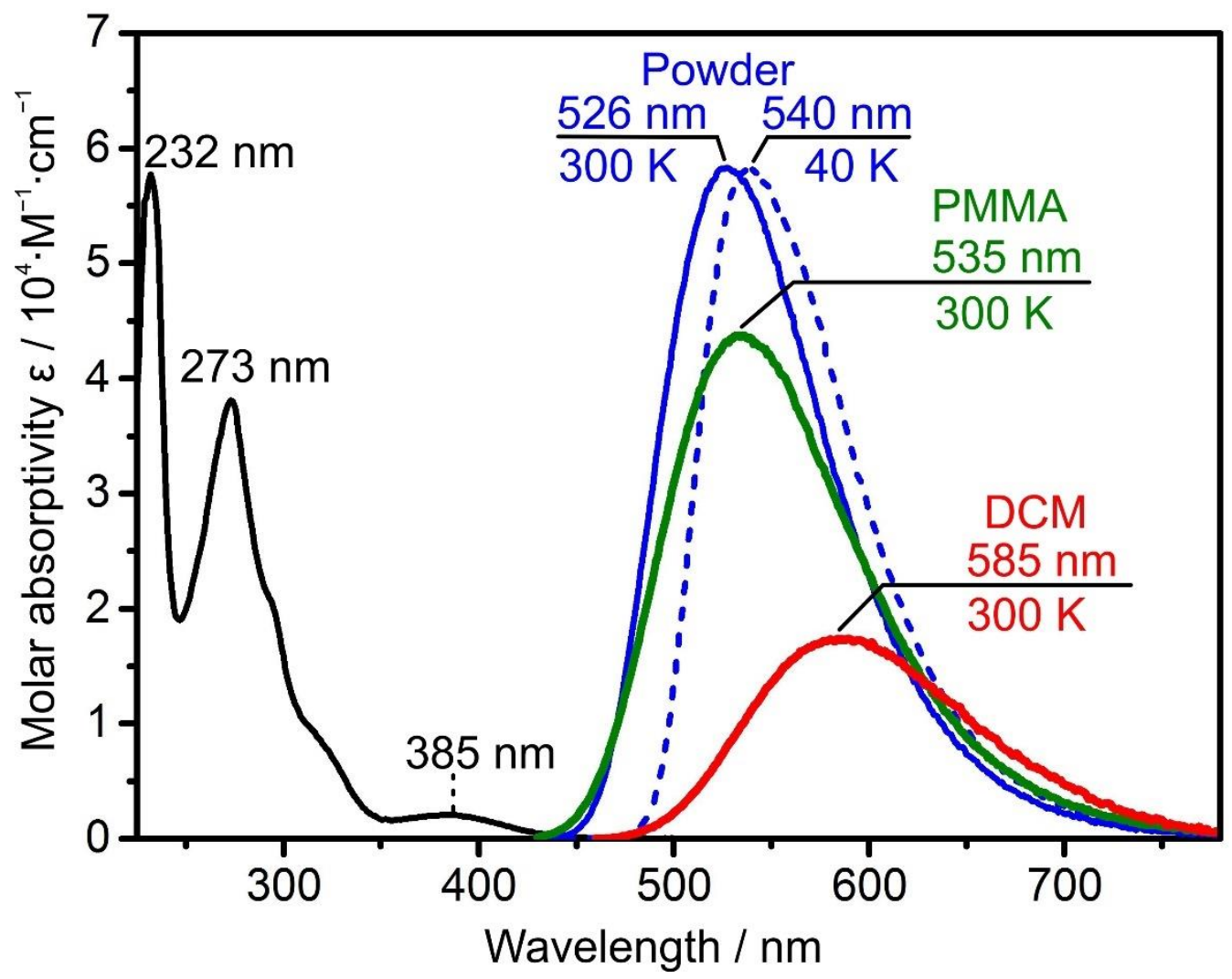

Figure 3. Absorption spectrum of $\mathrm{Ag}(\mathrm{dbp})\left(\mathrm{P}_{2}-\mathrm{nCB}\right)$ measured in dichloromethane $(\mathrm{DCM})$ at $300 \mathrm{~K}$ (black line) and emission spectra of $\mathrm{Ag}(\mathrm{dbp})\left(\mathrm{P}_{2}-\mathrm{nCB}\right)$ shown in 
colored lines $\left(\lambda_{\mathrm{exc}}=410 \mathrm{~nm}\right)$ measured at different conditions. The DCM solutions were of $\approx 10^{-5} \mathrm{M}$ concentration. The PMMA film was doped with $\approx 1$ wt. $\%$ of the complex.

The emission spectra displayed in Figure 3 are broad and unstructured even if cooled to $\mathrm{T}=40 \mathrm{~K}$ (or $1.6 \mathrm{~K}$, not reproduced). The emission of $\mathrm{Ag}(\mathrm{dbp})\left(\mathrm{P}_{2}-\mathrm{nCB}\right)$ doped in PMMA $\left(\lambda_{\max }=535 \mathrm{~nm}\right)$ and dissolved in $\operatorname{DCM}\left(\lambda_{\max }=585 \mathrm{~nm}\right)$ is red-shifted compared to the emission measured in powder by $9 \mathrm{~nm}$ and $59 \mathrm{~nm}$, respectively. This is related to a flattening distortion of $A g(d b p)\left(P_{2}-n C B\right)$ induced by the CT excitation, as predicted by the theoretical calculations presented in Section 3. In particular, the data show that the distortion-related red shift becomes more pronounced with decreasing rigidity of the environment. (The blue shift of $14 \mathrm{~nm}$ as observed on cooling is a consequence of the TADF effect and is discussed below.) Moreover, usually such structural changes are connected with an increase of non-radiative decay rates or reductions of the emission quantum yields due to increasing Franck-Condon (FC) factors of higher excited vibrational wavefunctions of the electronic ground state and of energetically lower vibrational wavefunctions of the electronically excited state. ${ }^{48,85}$ Indeed, this is also observed for $A g(d b p)\left(P_{2}-n C B\right)$, for which the quantum yield decreases (under degassed conditions) from $\Phi_{\mathrm{PL}}($ powder $)=100 \%$ to $\Phi_{\mathrm{PL}}(\mathrm{PMMA})=85$ $\%$ and to $\Phi_{\mathrm{PL}}(\mathrm{DCM})=3 \%$. Similar trends have already been reported for $\mathrm{Cu}(\mathrm{I})$ compounds ${ }^{24,34}$, though the decrease of $\Phi_{\mathrm{PL}}$ is usually more distinct than found for $\mathrm{Ag}(\mathrm{dbp})\left(\mathrm{P}_{2}-\mathrm{nCB}\right)$. Obviously, the title compound is rather rigid due to its specific molecular structure. The data of the emission peak positions and the quantum yields are summarized in Table 1.

\subsection{Thermally activated delayed fluorescence and drastic increase of the}

\section{emission decay rate}

For a deeper photophysical characterization of the TADF properties, investigation of the broad emission spectra is not promising. However, the alternative spectroscopic method, based on temperature- and time-resolving measurements can be applied. Presumably this is the only procedure that allows us to obtain detailed insight into electronic structures in such cases. Corresponding studies are carried out for $\mathrm{Ag}(\mathrm{dbp})\left(\mathrm{P}_{2}-\mathrm{nCB}\right)$ powders. ${ }^{86}$ 

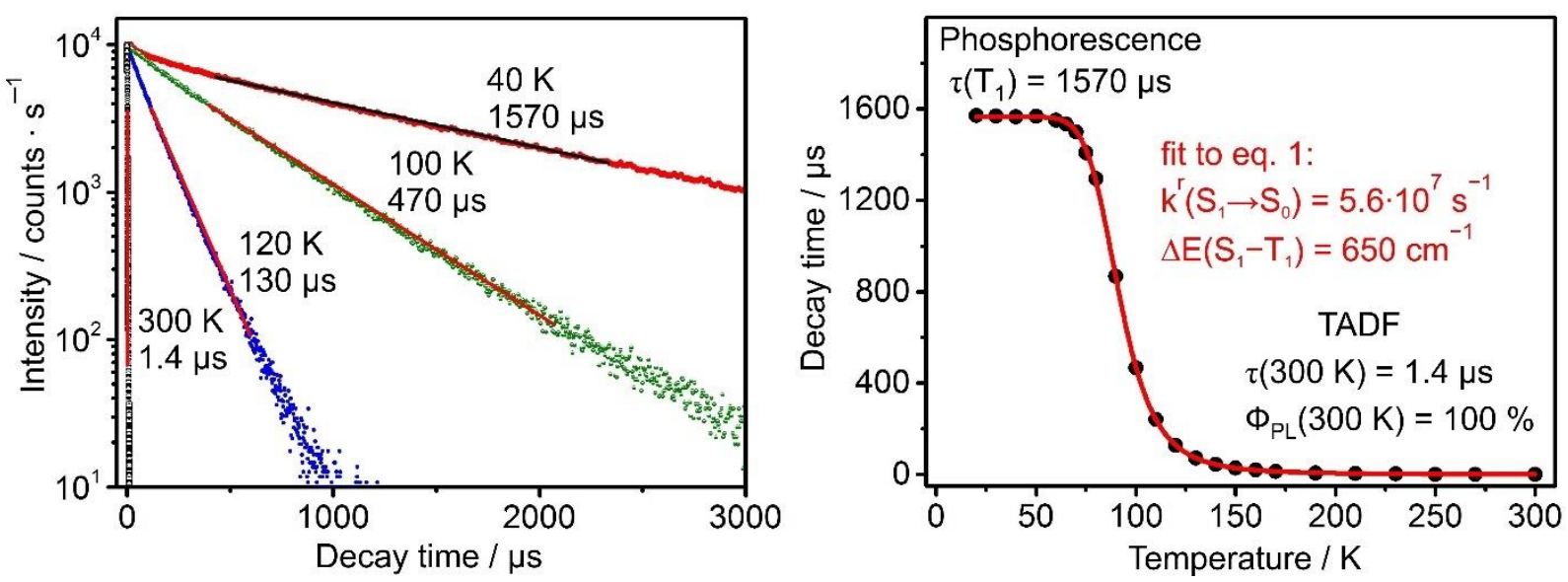

Figure 4. Left: luminescence decay times $(\tau)$ of $A g(d b p)\left(P_{2}-n C B\right)$ powder measured at different temperatures; Right: The luminescence decay times $(\tau)$ plotted versus temperature. The values of $\mathrm{k}\left(\mathrm{S}_{1} \rightarrow \mathrm{S}_{0}\right)=5.6 \cdot 10^{7} \mathrm{~s}^{-1}(18 \mathrm{~ns})$ and $\Delta \mathrm{E}\left(\mathrm{S}_{1}-\mathrm{T}_{1}\right)=650 \mathrm{~cm}^{-1}$ result from a fit of eq. 1 to the experimental $\tau(\mathrm{T})$ values, with $\tau\left(\mathrm{T}_{1}\right)$ fixed to $1570 \mu \mathrm{s}$ as determined directly for $\mathrm{T}<60 \mathrm{~K}$ (plateau).

Figure 4 (left) displays emission decay curves measured at different temperatures. By use of the emission quantum yields and the decay times (Table 1), one can determine that the radiative decay rate $\mathrm{k}^{r}=\Phi_{\mathrm{PL}} / \tau$ increases from $\mathrm{k}^{\mathrm{r}}(40 \mathrm{~K})=5.5 \cdot 10^{2} \mathrm{~s}^{-1}$ (assuming the same quantum yield as found for $T=77)$ to $k^{r}(300 K)=7.1 \cdot 10^{5} \mathrm{~s}^{-1}$. This corresponds to an increase by factor of almost 1300 . Obviously, such changes have to be related to the involvement of different electronic transitions at low and high temperature, respectively. They correspond to emissions from the $T_{1}$ and $S_{1}$ state to the ground state, respectively. Moreover, the decays are mono-exponential. Thus, we can conclude that the ISC time is fast (compare also refs. ${ }^{66,69,87}$ ) and that the two states are thermally equilibrated faster than the measured decay times. In this situation, the emission decay time $\tau(T)$ of the system of two states can be expressed by: $: 2,25,34,78,88$

$$
\tau(\mathrm{T})=\frac{3+\exp -\frac{\Delta \mathrm{E}\left(\mathrm{S}_{1}-\mathrm{T}_{1}\right)}{k_{\mathrm{B}} \mathrm{T}}}{3 \mathrm{k}\left(\mathrm{T}_{1}\right)+\mathrm{k}\left(\mathrm{S}_{1}\right) \exp -\frac{\Delta \mathrm{E}\left(\mathrm{S}_{1}-\mathrm{T}_{1}\right)}{k_{\mathrm{B}} \mathrm{T}}}
$$

wherein $k\left(T_{1}\right)=1 / \tau\left(T_{1}\right)$ and $k\left(S_{1}\right)=1 / \tau\left(S_{1}\right)$ are the decay rates with the decay times $\tau\left(T_{1}\right)$ and $\tau\left(S_{1}\right)$ of the triplet and singlet excited state, respectively, $\Delta E\left(S_{1}-T_{1}\right)$ is the energy separation between the $S_{1}$ and $T_{1}$ state and $k_{\mathrm{B}}$ is the Boltzmann constant.

In Figure 4 (right), the decay time is plotted versus temperature. At low temperature, 20 $\mathrm{K} \leq \mathrm{T} \leq 60 \mathrm{~K}$, a constant value of $1570 \mu$ s is observed (plateau). It represents the phosphorescence decay time $\tau\left(T_{1}\right)$ for the $T_{1} \rightarrow S_{0}$ transition. Phosphorescence decay 
times of the order of milliseconds were found also for other $\mathrm{Ag}(\mathrm{I})$ and $\mathrm{Cu}(\mathrm{I})$ compounds. ${ }^{29,34,49,51,74}$ This long decay displays the spin-forbiddenness of this transition. Obviously, SOC to adequate singlet states is weak. According to the discussion presented in Section 3, the next singlet state $\left(S_{4}\right)$ that exhibits a different $4 d$ orbital character than the $\mathrm{T}_{1}$ state and that can induce $\mathrm{SOC}$ (following general quantum mechanical rules $\left.{ }^{76-78}\right)$ is energetically far, with $\Delta E\left(S_{4}-T_{1}\right)=1.57 \mathrm{eV}$. Hence, the singlet character mixed into the $T_{1}$ state is very small.

For $\mathrm{T}>60 \mathrm{~K}$, the decay time becomes shorter with increasing temperature due to a thermal population of the higher lying $S_{1}$ state. $A$ plot of the $\tau$ values versus temperature has a characteristic form of an s-shaped curve with the point of maximum slope at $\mathrm{T}=90 \mathrm{~K}(\tau=870 \mu \mathrm{s})$ (Figure 4). For $\mathrm{T}>200 \mathrm{~K}$, the $\tau(\mathrm{T})$ values decrease only slightly and reach at ambient temperature $\tau(300 \mathrm{~K})=1.4 \mu \mathrm{s}$. The $\tau(\mathrm{T})$ data can be perfectly fitted to eq. (1) (Figure 4) giving the activation energy of $\Delta \mathrm{E}\left(\mathrm{S}_{1}-\mathrm{T}_{1}\right)=650 \mathrm{~cm}^{-1}$ and the radiative rate of the prompt fluorescence of $k^{r}\left(S_{1} \rightarrow S_{0}\right)=5.6 \cdot 10^{7} \mathrm{~s}^{-1}$ formally corresponding to the prompt fluorescence decay time of $\tau\left(S_{1}\right)=18 \mathrm{~ns}$. It is remarked that the related prompt fluorescence is not directly observed, since the ISC processes from $S_{1}$ to $T_{1}$ are about three orders of magnitude faster (Compare refs. ${ }^{66,69,87}$ ).

The experimental value of $\mathrm{k}\left(\mathrm{S}_{1} \rightarrow \mathrm{S}_{0}\right)=5.6 \cdot 10^{7} \mathrm{~s}^{-1}$ found for the prompt fluorescence rate is remarkably large. $\mathrm{Cu}(\mathrm{I})$ complexes investigated so far (and that have comparable $\Delta E\left(S_{1}-T_{1}\right)$ splittings) exhibit only rates being more than one order of magnitude smaller. ${ }^{34}$ Thus, the large (prompt) fluorescence rate is identified as the key factor leading to the exceptionally fast TADF decay time of $\mathrm{Ag}(\mathrm{dbp})\left(\mathrm{P}_{2}-\mathrm{nCB}\right)$. This behavior fits perfectly to the large oscillator strength that is calculated for the $S_{1} \rightarrow S_{0}$ transition (Section 3). The theoretical value of oscillator strength is also more than one order of magnitude larger than for any other TADF complex reported so far (Section 3). ${ }^{42,49}$ 
Table 1 summarizes the emission data that characterize $\mathrm{Ag}(\mathrm{dbp})(\mathrm{P} 2-\mathrm{nCB})$. Due to the extraordinarily large radiative TADF decay rate of $\mathrm{k}^{\mathrm{r}}(300 \mathrm{~K})=7.1 \cdot 10^{5} \mathrm{~s}^{-1}$, the emission quantum yield reaches $\Phi_{\mathrm{PL}}(\mathrm{TADF})=100 \%$. Interestingly at $\mathrm{T}=77 \mathrm{~K}$, the quantum yield amounts only to $\Phi_{\mathrm{PL}}(77 \mathrm{~K})=87 \%$, since at that temperature the decay time is as long as $\tau(77 \mathrm{~K})=1300 \mu$ s giving a radiative rate of $\mathrm{k}^{\mathrm{r}}(77 \mathrm{~K})=6.7 \cdot 10^{2} \mathrm{~s}^{-1}$. According to $\mathrm{k}^{\mathrm{nr}}=$ $\left(1-\Phi_{\mathrm{PL}}\right) / \tau$, the non-radiative rate is determined to $\mathrm{krr}^{\mathrm{nr}}=1 \cdot 10^{2} \mathrm{~s}^{-1}$. Thus, at $\mathrm{T}=77 \mathrm{~K}$ the non-radiative process can moderately compete with the radiative process, but not at ambient temperature.

Table 1. Emission data of $\mathrm{Ag}(\mathrm{dbp})\left(\mathrm{P}_{2}-\mathrm{nCB}\right)$ in different environments.

powder PMMA $\mathrm{CH}_{2} \mathrm{Cl}_{2}$

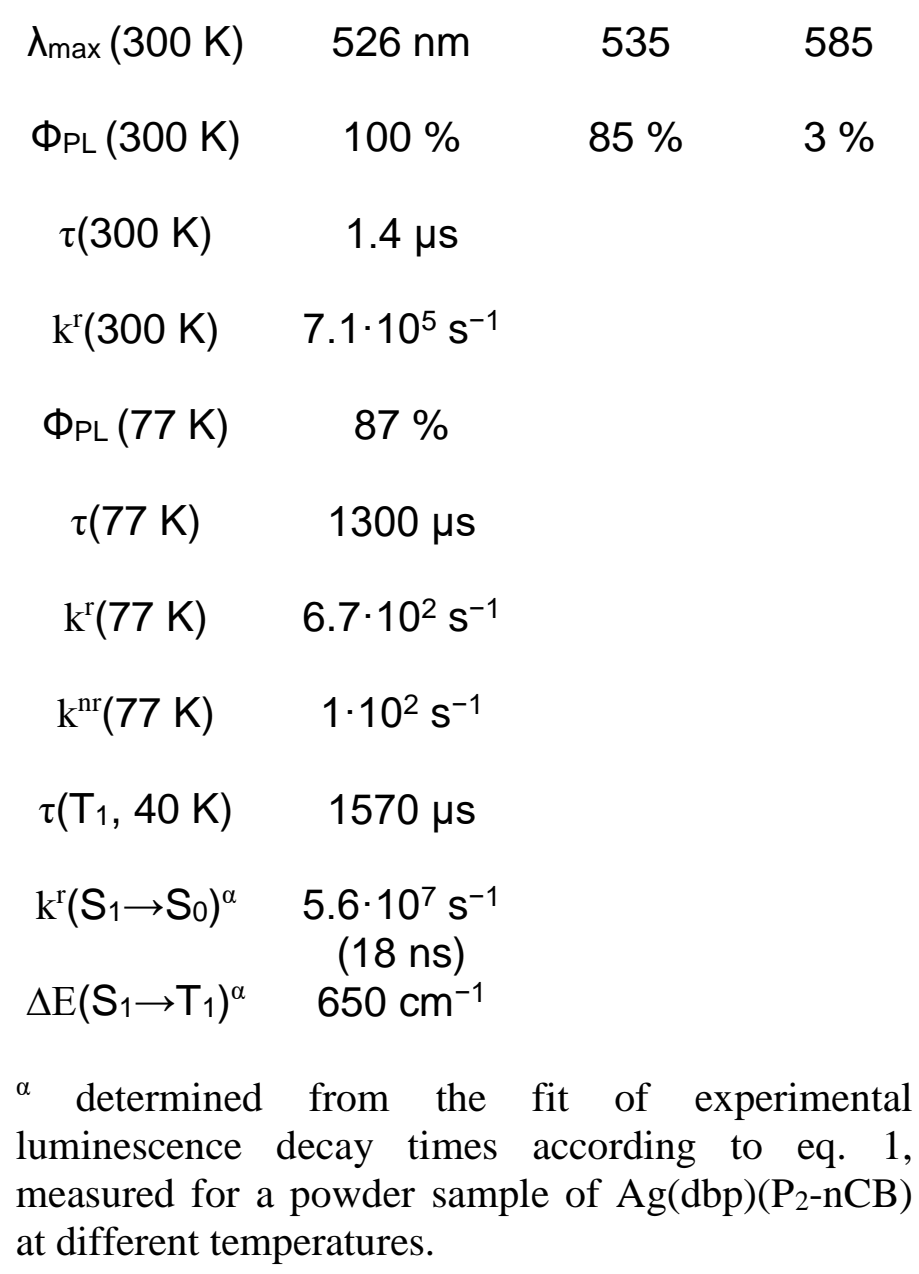

\subsection{TADF highlights}


In Figure 5, we highlight the $\mathrm{Ag}(\mathrm{dbp})\left(\mathrm{P}_{2}-\mathrm{nCB}\right)$ material's TADF properties. At low temperature $\left(\mathrm{T}<60 \mathrm{~K}\right.$ ), one observes only long-living phosphorescence as $\mathrm{T}_{1} \rightarrow \mathrm{S}_{0}$ transition decaying with $\tau=1570 \mu \mathrm{s}$. With temperature increase $\left(k_{B} T\right)$, up-ISC (or reverse ISC, RISC) leads to a population of the $S_{1}$ state that lies higher in energy than $\mathrm{T}_{1}$. Accordingly, a blue shifted TADF emission of $14 \mathrm{~nm}\left(\approx 500 \mathrm{~cm}^{-1}\right)$ is found (Figure 3). This value corresponds well to the activation energy of $\Delta E\left(S_{1}-T_{1}\right)=650 \mathrm{~cm}^{-1}$ resulting from the decay times' analysis (Figure 4).

Since, the $S_{1} \rightarrow S_{0}$ transition rate is much higher than of any other organo-metallic TADF material, the TADF decay time drops to the extremely small value of $\tau($ TADF, $300 \mathrm{~K})=$ $1.4 \mu \mathrm{s}$. As a consequence of the related high radiative TADF decay rate, the emission quantum yield reaches $100 \%$ at ambient temperature.

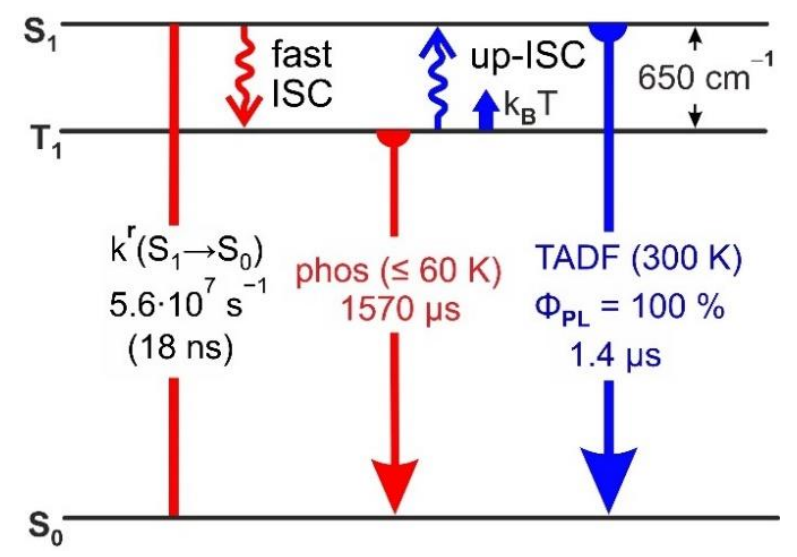

Figure 5. Photophysical properties of $\mathrm{Ag}(\mathrm{dbp})\left(\mathrm{P}_{2}-\mathrm{nCB}\right)$ as a powder sample shown on a simplified energy diagram. Sometimes up-ISC is also called reverse ISC (RISC).

\section{Summarizing conclusions}

Thermally activated delayed fluorescence is known at least since the pioneering work of Parker et al. ${ }^{89}$ But only recently, a deeper scientific interest was stimulated by applicability of TADF materials as emitters in OLEDs, as proposed first in the patent literature. ${ }^{27}$ In particular, it became a challenge to develop efficient TADF materials based on purely organic molecules ${ }^{26,45,46}$ as well as on organo-transition metals 
complexes. Within the manifold of transition metal compounds, so far mainly $\mathrm{Cu}(\mathrm{I})^{33,34}$ complexes with distinct MLCT character in the lowest excited states were subject of detailed investigations. Only a few TADF reports exist for $\operatorname{Pd}(0),{ }^{90} \operatorname{Pt}(0),{ }^{90,91}$ and $\mathrm{Ag}(\mathrm{I})^{37,50,51}$ based compounds. In all cases, low-lying charge-transfer (CT) transitions result in relatively small exchange splittings and hence, relatively small singlet-triplet energy separations $\Delta E\left(S_{1}-T_{1}\right)$ as required for efficient TADF materials.

It is a challenge to design $\mathrm{Ag}(\mathrm{I})$ complexes with low-lying CT-type excited states that involve significant metal $4 d$-character, since most compounds exhibit low-lying ${ }^{1,3} \pi \pi^{*}$ states (that do not show TADF). ${ }^{53}$ This problem could be resolved by designing a $\mathrm{Ag}(\mathrm{I})$ complex with a strongly electron-donating negatively charged diphosphine-nidocarborane $\left(\mathrm{P}_{2}-\mathrm{nCB}\right)$ ligand.

For TADF materials, in particular, if applied in OLEDs, it is a further challenge to minimize the TADF decay time (at high emission quantum yield). Eq. (1) shows that three parameters govern this decay time: (i) $\Delta \mathrm{E}\left(\mathrm{S}_{1}-\mathrm{T}_{1}\right)$ should be small, as is frequently discussed. 26,33,34,37,43,46,49,50,92,93 (ii) The phosphorescence decay rate $\mathrm{k}\left(\mathrm{T}_{1} \rightarrow \mathrm{S}_{0}\right)$ should be high, which can be obtained for compounds that show high SOC with respect to the lowest triplet state. ${ }^{30,32-34}$ (iii) The allowedness of the $S_{1} \leftrightarrow S_{0}$ transition, described by the rate of the prompt fluorescence $\mathrm{k}\left(\mathrm{S}_{1} \rightarrow \mathrm{S}_{0}\right)$ or the corresponding oscillator strength should be high, however, without increasing $\Delta \mathrm{E}\left(\mathrm{S}_{1}-\mathrm{T}_{1}\right)$. For the first time this problem is addressed and solved. For the title compound, experimental as well as TD-DFT calculations reveal that the radiative rate $\mathrm{k}^{\mathrm{r}}\left(\mathrm{S}_{1} \rightarrow \mathrm{S}_{0}\right)$ (or the oscillator strength) are more than one order of magnitude higher than found for any other organo-metallic TADF material with similar $\Delta \mathrm{E}\left(\mathrm{S}_{1}-\mathrm{T}_{1}\right)$ splitting.

In conclusion, the high $S_{1} \rightarrow S_{0}$ allowedness found for the title compound leads to the attractive emission properties of $\mathrm{Ag}(\mathrm{dbp})\left(\mathrm{P}_{2}-\mathrm{nCB}\right)$, exhibiting a quantum yield of $\Phi_{\mathrm{PL}}=$ $100 \%$ at a decay time of $\tau($ TADF $)=1.4 \mu \mathrm{s}$. This represents the shortest radiative 
decay time of any TADF material reported so far. Moreover, this is the first TADF material with a radiative decay time being comparable to $\operatorname{Ir}(\mathrm{III})$ complexes $^{78,94}$ applied in OLEDs.

\section{ASSOCIATED CONTENT}

*Supporting Information

The Supporting Information is available free of charge on the

ACS Publications website DOI:

Experimental details, synthetic procedures, compound characterizations of the synthesized ligand and complex, photophysical instrumentation, X-ray data, computational details, calculated geometries in $\mathrm{XYZ}$ format, excited-state energies, dominant orbital excitations from TD-DFT calculations, contour plots of the molecular orbitals that participate in the formation of the discussed excited states, calculated molecular orbital compositions (PDF) (TXT) (CIF)

\section{Acknowledgements}

The authors thank the German Ministry of Education and Research for financial support in the scope of the cyCESH project (FKN 13N12668). MZS gratefully acknowledges Professor Duncan Bruce (York) and The University of York for providing computational facilities. RC thanks the European Research Council (ERC) for support in the framework of the MSCA RISE Project no. 645628. AS acknowledges the German Academic Exchange Service (DAAD) for support.

\section{References}

(1) Yersin, H., Highly Efficient OLEDs with Phosphorescent Materials. Wiley-VCH: Weinheim, 2008.

(2) Brütting, W.; Adachi, C., Physics of Organic Semiconductors. Wiley-VCH: Weinheim, 2012 .

(3) Kim, Y.; Park, S.; Lee, Y. H.; Jung, J.; Yoo, S.; Lee, M. H. Homoleptic Tris-Cyclometalated Iridium Complexes with Substituted o-Carboranes: Green Phosphorescent Emitters for Highly Efficient Solution-Processed Organic Light-Emitting Diodes. Inorg. Chem. 2016, 55, 909-917. 
(4) Liu, Z.; Qiu, J.; Wei, F.; Wang, J.; Liu, X.; Helander, M. G.; Rodney, S.; Wang, Z.; Bian, Z.; Lu, Z.; Thompson, M. E.; Huang, C. Simple and High Efficiency Phosphorescence Organic Light-Emitting Diodes with Codeposited Copper(I) Emitter. Chem. Mater. 2014, 26, 2368-2373. (5) Zhang, X. Q.; Xie, Y. M.; Zheng, Y.; Liang, F.; Wang, B.; Fan, J.; Liao, L. S. Highly phosphorescent platinum(II) complexes based on rigid unsymmetric tetradentate ligands. Org. Electron. phys. mater. appl. 2016, 32, 120-125.

(6) Kim, J.; Lee, K. H.; Lee, S. J.; Lee, H. W.; Kim, Y. K.; Kim, Y. S.; Yoon, S. S. Red Phosphorescent Bis-Cyclometalated Iridium Complexes with Fluorine-, Phenyl-, and Fluorophenyl-Substituted 2-Arylquinoline Ligands. Chem. Eur. J. 2016, 22, 4036-4045.

(7) Wong, M. Y.; Hedley, G. J.; Xie, G.; Kölln, L. S.; Samuel, I. D. W.; Pertegás, A.; Bolink, H. J.; Zysman-Colman, E. Light-Emitting Electrochemical Cells and Solution-Processed Organic Light-Emitting Diodes Using Small Molecule Organic Thermally Activated Delayed Fluorescence Emitters. Chem. Mater. 2015, 27, 6535-6542.

(8) Minaev, B.; Baryshnikov, G.; Agren, H. Principles of phosphorescent organic light emitting devices. Phys. Chem. Chem. Phys. 2014, 16, 1719-1758.

(9) Yersin, H.; Rausch, A. F.; Czerwieniec, R., Organometallic Emitters for OLEDs. Triplet Harvesting, Singlet Harvesting, Case Structures, and Trends. In Physics of Organic Semiconductors, 2 ed.; Brütting, W.; Adachi, C., Eds. Wiley-VCH: Weinheim, 2012; pp 371425.

(10) Sun, Y.; Giebink, N. C.; Kanno, H.; Ma, B.; Thompson, M. E.; Forrest, S. R. Management of singlet and triplet excitons for efficient white organic light-emitting devices. Nature 2006, 440, 908-912.

(11) Adachi, C.; Baldo, M. A.; Thompson, M. E.; Forrest, S. R. Nearly 100\% internal phosphorescence efficiency in an organic light emitting device. J. Appl. Phys. 2001, 90, 50485051.

(12) Lamansky, S.; Djurovich, P.; Murphy, D.; Abdel-Razzaq, F.; Lee, H. E.; Adachi, C.; Burrows, P. E.; Forrest, S. R.; Thompson, M. E. Highly phosphorescent bis-cyclometalated iridium complexes: Synthesis, photophysical characterization, and use in organic light emitting diodes. J. Am. Chem. Soc. 2001, 123, 4304-4312.

(13) Kim, S. Y.; Jeong, W. I.; Mayr, C.; Park, Y. S.; Kim, K. H.; Lee, J. H.; Moon, C. K.; Brütting, W.; Kim, J. J. Organic light-emitting diodes with $30 \%$ external quantum efficiency based on a horizontally oriented emitter. Adv. Func. Mater. 2013, 23, 3896-3900.

(14) Schmidt, T. D.; Reichardt, L. J.; Rausch, A. F.; Wehrmeister, S.; Scholz, B. J.; Mayr, C.; Wehlus, T.; Ciarnáin, R. M.; Danz, N.; Reusch, T. C. G.; Brütting, W. Extracting the emitter 
orientation in organic light-emitting diodes from external quantum efficiency measurements. Appl. Phys. Lett. 2014, 105, DOI: 10.1063/1.4891680.

(15) Cherpak, V.; Stakhira, P.; Minaev, B.; Baryshnikov, G.; Stromylo, E.; Helzhynskyy, I.; Chapran, M.; Volyniuk, D.; Tomkuté-Lukšiené, D.; Malinauskas, T.; Getautis, V.; Tomkeviciene, A.; Simokaitiene, J.; Grazulevicius, J. V. Efficient "warm-white" OLEDs based on the phosphorescent bis-cyclometalated iridium(III) complex. J. Phys. Chem. C 2014, 118, 11271-11278.

(16) Yang, C. H.; Beltran, J.; Lemaur, V.; Cornil, J.; Hartmann, D.; Sarfert, W.; Fröhlich, R.; Bizzarri, C.; De Cola, L. Iridium metal complexes containing N-heterocyclic carbene ligands for blue-light-emitting electrochemical cells. Inorg. Chem. 2010, 49, 9891-9901.

(17) Henwood, A. F.; Zysman-Colman, E. Luminescent Iridium Complexes Used in LightEmitting Electrochemical Cells (LEECs). Top. Curr. Chem. 2016, 374, DOI: 10.1007/s41061016-0036-0.

(18) Pal, A. K.; Cordes, D. B.; Slawin, A. M. Z.; Momblona, C.; Ortí, E.; Samuel, I. D. W.; Bolink, H. J.; Zysman-Colman, E. Synthesis, Properties, and Light-Emitting Electrochemical Cell (LEEC) Device Fabrication of Cationic Ir(III) Complexes Bearing Electron-Withdrawing Groups on the Cyclometallating Ligands. Inorg. Chem. 2016, 55, 10361-10376.

(19) Ertl, C. D.; Bolink, H. J.; Housecroft, C. E.; Constable, E. C.; Ortí, E.; JunqueraHernández, J. M.; Neuburger, M.; Shavaleev, N. M.; Nazeeruddin, M. K.; Vonlanthen, D. BisSulfone- and Bis-Sulfoxide-Spirobifluorenes: Polar Acceptor Hosts with Tunable Solubilities for Blue-Phosphorescent Light-Emitting Devices. Eur. J. Org. Chem. 2016, 2016, 2037-2047.

(20) Helfrich, W.; Schneider, W. G. Transients of Volume-Controlled Current and of Recombination Radiation in Anthracene. J. Chem. Phys. 1966, 44, 2902-2909.

(21) Rausch, A. F.; Thompson, M. E.; Yersin, H. Matrix effects on the triplet state of the OLED emitter Ir(4,6-dFppy)2(pic) (FIrpic): investigations by high-resolution optical spectroscopy. Inorg. Chem. 2009, 48, 1928-1937.

(22) Lamansky, S.; Kwong, R. C.; Nugent, M.; Djurovich, P. I.; Thompson, M. E. Molecularly doped polymer light emitting diodes utilizing phosphorescent $\mathrm{Pt}(\mathrm{II})$ and $\operatorname{Ir}(\mathrm{III})$ dopants. Org. Electron. 2001, 2, 53-62.

(23) Yersin, H. Triplet emitters for OLED applications. Mechanisms of exciton trapping and control of emission properties. Top. Curr. Chem. 2004, 241, 1-26.

(24) Czerwieniec, R.; Yu, J.; Yersin, H. Blue-light emission of $\mathrm{Cu}(\mathrm{I})$ complexes and singlet harvesting. Inorg. Chem. 2011, 50, 8293-8301.

(25) Deaton, J. C.; Switalski, S. C.; Kondakov, D. Y.; Young, R. H.; Pawlik, T. D.; Giesen, D. J.; Harkins, S. B.; Miller, A. J. M.; Mickenberg, S. F.; Peters, J. C. E-type delayed fluorescence 
of a phosphine-supported cu 2( $\mu$-nar 2) 2 diamond core: Harvesting singlet and triplet excitons in OLEDs. J. Am. Chem. Soc. 2010, 132, 9499-9508.

(26) Uoyama, H.; Goushi, K.; Shizu, K.; Nomura, H.; Adachi, C. Highly efficient organic lightemitting diodes from delayed fluorescence. Nature 2012, 492, 234-238.

(27) Yersin, H.; Monkowius, U. Komplexe mit kleinen Singulett-Triplett-Energie-Abständen zur Verwendung in opto-elektronischen Bauteilen (Singulett-Harvesting-Effekt). DE 102008 033563, 2008.

(28) Hong, X.; Wang, B.; Liu, L.; Zhong, X. X.; Li, F. B.; Wang, L.; Wong, W. Y.; Qin, H. M.; Lo, Y. H. Highly efficient blue-green neutral dinuclear copper(I) halide complexes containing bidentate phosphine ligands. J. Lumin. 2016, 180, 64-72.

(29) Leitl, M. J.; Küchle, F.-R.; Mayer, H. A.; Wesemann, L.; Yersin, H. Brightly Blue and Green Emitting $\mathrm{Cu}(\mathrm{I})$ Dimers for Singlet Harvesting in OLEDs. J. Phys. Chem. A 2013, 117, 11823-11836.

(30) Leitl, M. J.; Krylova, V. A.; Djurovich, P. I.; Thompson, M. E.; Yersin, H. Phosphorescence versus Thermally Activated Delayed Fluorescence. Controlling Singlet-Triplet Splitting in Brightly Emitting and Sublimable Cu(I) Compounds. J. Am. Chem. Soc. 2014, 136, 16032-16038.

(31) Linfoot, C. L.; Leitl, M. J.; Richardson, P.; Rausch, A. F.; Chepelin, O.; White, F. J.; Yersin, H.; Robertson, N. Thermally Activated Delayed Fluorescence (TADF) and enhancing photoluminescence quantum yields of [CuI(diimine)(diphosphine)]+ complexes - Photophysical, structural, and computational studies. Inorg. Chem. 2014, 53, 10854-10861.

(32) Hofbeck, T.; Monkowius, U.; Yersin, H. Highly Efficient Luminescence of $\mathrm{Cu}(\mathrm{I})$ Compounds: Thermally Activated Delayed Fluorescence Combined with Short-Lived Phosphorescence. J. Am. Chem. Soc. 2015, 137, 399-404.

(33) Leitl, M. J.; Zink, D. M.; Schinabeck, A.; Baumann, T.; Volz, D.; Yersin, H. Copper(I) Complexes for Thermally Activated Delayed Fluorescence: From Photophysical to Device Properties. Top. Curr. Chem. 2016, 374, 25.

(34) Czerwieniec, R.; Leitl, M. J.; Homeier, H. H. H.; Yersin, H. Cu(I) complexes - Thermally activated delayed fluorescence. Photophysical approach and material design. Coord. Chem. Rev. 2016, 325, 2-28.

(35) Chen, X. L.; Yu, R.; Wu, X. Y.; Liang, D.; Jia, J. H.; Lu, C. Z. A strongly greenish-blueemitting $\mathrm{Cu} 4 \mathrm{Cl} 4$ cluster with an efficient spin-orbit coupling (SOC): Fast phosphorescence: Versus thermally activated delayed fluorescence. Chem. Commun. 2016, 52, 6288-6291. 
(36) Ohara, H.; Kobayashi, A.; Kato, M. Simple and extremely efficient blue emitters based on mononuclear $\mathrm{Cu}(\mathrm{I})$-halide complexes with delayed fluorescence. Dalton Trans. 2014, 43, 17317-17323.

(37) Osawa, M.; Kawata, I.; Ishii, R.; Igawa, S.; Hashimoto, M.; Hoshino, M. Application of neutral d10 coinage metal complexes with an anionic bidentate ligand in delayed fluorescencetype organic light-emitting diodes. J. Mater. Chem. C 2013, 1, 4375-4383.

(38) Bergmann, L.; Friedrichs, J.; Mydlak, M.; Baumann, T.; Nieger, M.; Bräse, S. Outstanding luminescence from neutral copper(I) complexes with pyridyl-tetrazolate and phosphine ligands. Chem. Commun. 2013, 49, 6501-6503.

(39) Armaroli, N.; Accorsi, G.; Holler, M.; Moudam, O.; Nierengarten, J. F.; Zhou, Z.; Wegh, R. T.; Welter, R. Highly luminescent Cu-I complexes for light-emitting electrochemical cells. Adv. Mater. 2006, 18, 1313-1316.

(40) Tsuboyama, A.; Kuge, K.; Furugori, M.; Okada, S.; Hoshino, M.; Ueno, K. Photophysical Properties of Highly Luminescent Copper(I) Halide Complexes Chelated with 1,2Bis(diphenylphosphino)benzene. Inorg. Chem. 2007, 46, 1992-2001.

(41) Cuttell, D. G.; Kuang, S. M.; Fanwick, P. E.; McMillin, D. R.; Walton, R. A. Simple Cu(I) complexes with unprecedented excited-state lifetimes. J. Am. Chem. Soc. 2002, 124, 6-7.

(42) Kang, L.; Chen, J.; Teng, T.; Chen, X. L.; Yu, R.; Lu, C. Z. Experimental and theoretical studies of highly emissive dinuclear $\mathrm{Cu}(\mathrm{I})$ halide complexes with delayed fluorescence. Dalton Trans. 2015, 44, 11649-11659.

(43) Zink, D. M.; Bächle, M.; Baumann, T.; Nieger, M.; Kühn, M.; Wang, C.; Klopper, W.; Monkowius, U.; Hofbeck, T.; Yersin, H.; Bräse, S. Synthesis, structure, and characterization of dinuclear copper(I) halide complexes with $\mathrm{P}^{\wedge} \mathrm{N}$ ligands featuring exciting photoluminescence properties. Inorg. Chem. 2013, 52, 2292-2305.

(44) Volz, D.; Chen, Y.; Wallesch, M.; Liu, R.; Fléchon, C.; Zink, D. M.; Friedrichs, J.; Flügge, H.; Steininger, R.; Göttlicher, J.; Heske, C.; Weinhardt, L.; Bräse, S.; So, F.; Baumann, T. Bridging the efficiency gap: Fully bridged dinuclear $\mathrm{Cu}(\mathrm{I})$-complexes for singlet harvesting in high-efficiency OLEDs. Adv. Mater. 2015, 27, 2538-2543.

(45) Zhang, Q.; Li, B.; Huang, S.; Nomura, H.; Tanaka, H.; Adachi, C. Efficient blue organic light-emitting diodes employing thermally activated delayed fluorescence. Nat. Photon. 2014, 8, 326-332.

(46) Kaji, H.; Suzuki, H.; Fukushima, T.; Shizu, K.; Suzuki, K.; Kubo, S.; Komino, T.; Oiwa, H.; Suzuki, F.; Wakamiya, A.; Murata, Y.; Adachi, C. Purely organic electroluminescent material realizing 100\% conversion from electricity to light. Nat. Commun. 2015, 6, 8476.

(47) Atkins, P. W., Quanta: A Handbook of Concepts. Oxford University Press: 1991; p 367. 
(48) Barltrop, J. A.; Coyle, J. D., Excited states in organic chemistry. Wiley: 1975; p 87.

(49) Czerwieniec, R.; Yersin, H. Diversity of Copper(I) Complexes Showing Thermally Activated Delayed Fluorescence: Basic Photophysical Analysis. Inorg. Chem. 2015, 54, 43224327.

(50) Chen, J.; Teng, T.; Kang, L.; Chen, X.-L.; Wu, X.-Y.; Yu, R.; Lu, C.-Z. Highly Efficient Thermally Activated Delayed Fluorescence in Dinuclear Ag(I) Complexes with a Bis-Bidentate Tetraphosphane Bridging Ligand. Inorg. Chem. 2016, 55, 9528-9536.

(51) Yersin, H.; Leitl, M. J.; Czerwieniec, R., TADF for singlet harvesting - Next generation OLED materials based on brightly green and blue emitting $\mathrm{Cu}(\mathrm{I})$ and $\mathrm{Ag}(\mathrm{I})$ compounds. In Proceedings of SPIE - The International Society for Optical Engineering, 2014; Vol. 9183.

(52) Kaeser, A.; Moudam, O.; Accorsi, G.; Séguy, I.; Navarro, J.; Belbakra, A.; Duhayon, C.; Armaroli, N.; Delavaux-Nicot, B.; Nierengarten, J. F. Homoleptic copper(I), silver(I), and gold(I) bisphosphine complexes. Eur. J. Inorg. Chem. 2014, 1345-1355.

(53) Hsu, C.-W.; Lin, C.-C.; Chung, M.-W.; Chi, Y.; Lee, G.-H.; Chou, P.-T.; Chang, C.-H.; Chen, P.-Y. Systematic Investigation of the Metal-Structure-Photophysics Relationship of Emissive d10-Complexes of Group 11 Elements: The Prospect of Application in Organic Light Emitting Devices. J. Am. Chem. Soc. 2011, 133, 12085-12099.

(54) Igawa, S.; Hashimoto, M.; Kawata, I.; Hoshino, M.; Osawa, M. Photoluminescence Properties, Molecular Structures, and Theoretical Study of Heteroleptic Silver(I) Complexes Containing Diphosphine Ligands. Inorg. Chem. 2012, 51, 5805-5813.

(55) Hsu, C.-C.; Lin, C.-C.; Chou, P.-T.; Lai, C.-H.; Hsu, C.-W.; Lin, C.-H.; Chi, Y. Harvesting Highly Electronically Excited Energy to Triplet Manifolds: State-Dependent Intersystem Crossing Rate in Os(II) and Ag(I) Complexes. J. Am. Chem. Soc. 2012, 134, 7715-7724.

(56) Kunkely, H.; Vogler, A. Optical properties of $\operatorname{Ag}($ tripod)X with tripod $=1,1,1$ tris(diphenyl-phosphinomethyl)ethane and $\mathrm{X}_{-}^{-}=\mathrm{Cl}-$ and $\mathrm{I}-$ : Intraligand and ligand-to-ligand charge transfer. Inorg. Chim. Acta. 2006, 359, 388-390.

(57) Crespo, O.; Gimeno, M. C.; Jones, P. G.; Laguna, A. Silver complexes with the nidodiphosphine [7,8-(PPh2)2-7,8-C2B9H10]. Dalton Trans. 1996, 4583-4588.

(58) Alexander, R. P.; Schroeder, H. Chemistry of Decaborane-Phosphorus Compounds. IV. Monomeric, Oligomeric, and Cyclic Phosphinocarboranes. Inorg. Chem. 1963, 2, 1107-1110.

(59) Teixidor, F.; Vinas, C.; Abad, M. M.; Kivekas, R.; Sillanpaa, R. The formation of nido [7,8-(PR2)2-7,8-C2B9H10]- from closo 1,2-(PR2)2-1,2-C2B10H10 (R = Ph, Et, iPr or OEt): a process enhanced by complexation. J. Organomet. Chem. 1996, 509, 139-150. 
(60) Teixidor, F.; Viñas, C.; Mar Abad, M.; Nuñez, R.; Kivekäs, R.; Sillanpäa, R. Procedure for the degradation of 1,2-(PR2)2-1,2-dicarba-closo-dodecaborane(12) and 1-(PR2)-2-R'-1,2dicarba-closo-dodecaborane(12). J. Organomet. Chem. 1995, 503, 193-203.

(61) Balakrishna, M. S.; Venkateswaran, R.; Mobin, S. M. Silver(I) complexes of bis[2(diphenylphosphino)phenyl] ether. Polyhedron 2008, 27, 899-904.

(62) Balakrishna, M. S.; Venkateswaran, R.; Mobin, S. M. Mixed-ligand silver(I) complexes containing bis[2-(diphenylphosphino)phenyl]ether and pyridyl ligands. Inorg. Chim. Acta. 2009, $362,271-276$.

(63) Cheng, G.; So, G. K.-M.; To, W.-P.; Chen, Y.; Kwok, C.-C.; Ma, C.; Guan, X.; Chang, X.; Kwok, W.-M.; Che, C.-M. Luminescent zinc(II) and copper(I) complexes for high-performance solution-processed monochromic and white organic light-emitting devices. Chem. Sci. 2015, 6, 4623-4635.

(64) Chen, L. X.; Jennings, G.; Liu, T.; Gosztola, D. J.; Hessler, J. P.; Scaltrito, D. V.; Meyer, G. J. Rapid Excited-State Structural Reorganization Captured by Pulsed X-rays. J. Am. Chem. Soc. 2002, 124, 10861-10867.

(65) Chen, L. X.; Shaw, G. B.; Novozhilova, I.; Liu, T.; Jennings, G.; Attenkofer, K.; Meyer, G. J.; Coppens, P. MLCT State Structure and Dynamics of a Copper(I) Diimine Complex Characterized by Pump-Probe X-ray and Laser Spectroscopies and DFT Calculations. J. Am. Chem. Soc. 2003, 125, 7022-7034.

(66) Iwamura, M.; Watanabe, H.; Ishii, K.; Takeuchi, S.; Tahara, T. Coherent Nuclear Dynamics in Ultrafast Photoinduced Structural Change of Bis(diimine)copper(I) Complex. J. Am. Chem. Soc. 2011, 133, 7728-7736.

(67) Armaroli, N.; Accorsi, G.; Cardinali, F.; Listorti, A., Photochemistry and Photophysics of Coordination Compounds: Copper. In Photochemistry and Photophysics of Coordination Compounds I, Balzani, V.; Campagna, S., Eds. Springer Berlin Heidelberg: Berlin, Heidelberg, 2007; pp 69-115.

(68) Lavie-Cambot, A.; Cantuel, M.; Leydet, Y.; Jonusauskas, G.; Bassani, D. M.; McClenaghan, N. D. Improving the photophysical properties of copper(I) bis(phenanthroline) complexes. Coord. Chem. Rev. 2008, 252, 2572-2584.

(69) Iwamura, M.; Takeuchi, S.; Tahara, T. Ultrafast Excited-State Dynamics of Copper(I) Complexes. Acc. Chem. Res. 2015, 48, 782-791.

(70) Garakyaraghi, S.; Danilov, E. O.; McCusker, C. E.; Castellano, F. N. Transient Absorption Dynamics of Sterically Congested Cu(I) MLCT Excited States. J. Phys. Chem. A 2015, 119, 3181-3193. 
(71) Dolomanov, O. V.; Bourhis, L. J.; Gildea, R. J.; Howard, J. A. K.; Puschmann, H. OLEX2: a complete structure solution, refinement and analysis program. J. Appl. Cryst. 2009, 42, 339341.

(72) Zhao, Y.; Truhlar, D. G. The M06 suite of density functionals for main group thermochemistry, thermochemical kinetics, noncovalent interactions, excited states, and transition elements: two new functionals and systematic testing of four M06-class functionals and 12 other functionals. Theor. Chem. Acc. 2007, 120, 215-241.

(73) Weigend, F.; Ahlrichs, R. Balanced basis sets of split valence, triple zeta valence and quadruple zeta valence quality for $\mathrm{H}$ to $\mathrm{Rn}$ : Design and assessment of accuracy. Phys. Chem. Chem. Phys. 2005, 7, 3297-3305.

(74) Matsumoto, K.; Shindo, T.; Mukasa, N.; Tsukuda, T.; Tsubomura, T. Luminescent Mononuclear $\mathrm{Ag}(\mathrm{I})-$ Bis(diphosphine) Complexes: Correlation between the Photophysics and the Structures of Mononuclear $\mathrm{Ag}(\mathrm{I})-\mathrm{Bis}($ diphosphine) Complexes. Inorg. Chem. 2010, 49, 805814.

(75) Osawa, M.; Hoshino, M. Photochemistry and photophysics of the tetrahedral silver(i) complex with diphosphine ligands: $\quad[\mathrm{Ag}(\mathrm{dppb}) 2] \mathrm{PF} 6 \quad(\mathrm{dppb} \quad=\quad 1, \quad 2-$ bis[diphenylphosphino]benzene). Chem. Commun. 2008, 6384-6386.

(76) Rausch, A. F.; Homeier, H. H. H.; Yersin, H. Organometallic Pt(II) and Ir(III) triplet emitters for OLED applications and the role of spin-orbit coupling: A study based on highresolution optical spectroscopy. Top. Organomet. Chem. 2010, 29, 193-235.

(77) Rausch, A. F.; Homeier, H. H. H.; Djurovich, P. I.; Thompson, M. E.; Yersin, H., Spinorbit coupling routes and OLED performance - Studies of blue-light emitting Ir(III) and Pt(II) complexes. In Proceedings of SPIE - The International Society for Optical Engineering, 2007; Vol. 6655.

(78) Yersin, H.; Rausch, A. F.; Czerwieniec, R.; Hofbeck, T.; Fischer, T. The triplet state of organo-transition metal compounds. Triplet harvesting and singlet harvesting for efficient OLEDs. Coord. Chem. Rev. 2011, 255, 2622-2652.

(79) Chen, J.-L.; Guo, Z.-H.; Luo, Y.-S.; Qiu, L.; He, L.-H.; Liu, S.-J.; Wen, H.-R.; Wang, J.-Y. Luminescent monometallic $\mathrm{Cu}(\mathrm{i})$ triphenylphosphine complexes based on methylated 5trifluoromethyl-3-(2'-pyridyl)-1,2,4-triazole ligands. New J. Chem. 2016, 40, 5325-5332.

(80) McCusker, C. E.; Castellano, F. N. Efficient Visible to Near-UV Photochemical Upconversion Sensitized by a Long Lifetime Cu(I) MLCT Complex. Inorg. Chem. 2015, 54, 6035-6042. 
(81) Liang, D.; Chen, X.-L.; Liao, J.-Z.; Hu, J.-Y.; Jia, J.-H.; Lu, C.-Z. Highly Efficient Cuprous Complexes with Thermally Activated Delayed Fluorescence for Solution-Processed Organic Light-Emitting Devices. Inorg. Chem. 2016, 55, 7467-7475.

(82) McCusker, C. E.; Castellano, F. N. Design of a Long-Lifetime, Earth-Abundant, Aqueous Compatible $\mathrm{Cu}(\mathrm{I})$ Photosensitizer Using Cooperative Steric Effects. Inorg. Chem. 2013, 52, 8114-8120.

(83) Wang, B.; Shelar, D. P.; Han, X.-Z.; Li, T.-T.; Guan, X.; Lu, W.; Liu, K.; Chen, Y.; Fu, W.-F.; Che, C.-M. Long-Lived Excited States of Zwitterionic Copper(I) Complexes for Photoinduced Cross-Dehydrogenative Coupling Reactions. Chem. Eur. J. 2015, 21, 1184-1190.

(84) Wang, Z.; Zheng, C.; Wang, W.; Xu, C.; Ji, B.; Zhang, X. Synthesis, Structure, and Photophysical Properties of Two Four-Coordinate $\mathrm{Cu}(\mathrm{I})-\mathrm{NHC}$ Complexes with Efficient Delayed Fluorescence. Inorg. Chem. 2016, 55, 2157-2164.

(85) Turro, N. J., Modern Molecular Photochemistry. University Science Books: 1991.

(86) For most compounds, the decay behavior measured of powder materials is modified, for example, by processes of energy transfer or triplet-triplet annihilation. However, in analogy to investigations of $\mathrm{Cu}(\mathrm{I}) \mathrm{TADF}$ materials [9, 24, 29, 34], also the low-lying $\mathrm{CT}$ states of $\mathrm{Ag}(\mathrm{dbp})(\mathrm{P} 2-\mathrm{nCB})$ exhibit geometry distortions even in the relatively rigid crystalline environment. These induce a localization (self-trapping). Thus, the emission of the powder material displays largely molecular properties. Accordingly, concentration quenching does not occur and the decay behavior does not show any distinctive features with concentration increase. (87) Bergmann, L.; Hedley, G. J.; Baumann, T.; Bräse, S.; Samuel, I. D. Direct observation of intersystem crossing in a thermally activated delayed fluorescence copper complex in the solid state. Sci. Adv. 2016, 2, e1500889.

(88) Azumi, T.; O'Donnell, C. M.; McGlynn, S. P. On the multiplicity of the phosphorescent state of organic molecules. J. Chem. Phys. 1966, 45, 2735-2742.

(89) Parker, C. A.; Hatchard, C. G. Triplet-singlet emission in fluid solutions. Phosphorescence of eosin. T. Faraday Soc. 1961, 57, 1894-1904.

(90) Tsubomura, T.; Ito, Y.; Inoue, S.; Tanaka, Y.; Matsumoto, K.; Tsukuda, T. Strongly luminescent palladium(0) and platinum(0) diphosphine complexes. Inorg. Chem. 2008, 47, 481486.

(91) Abedin-Siddique, Z.; Ohno, T.; Nozaki, K.; Tsubomura, T. Intense Fluorescence of Metalto-Ligand Charge Transfer in $\left[\operatorname{Pt}(0)\left(\right.\right.$ binap)2] [binap $=2,2^{`}$-Bis(diphenylphosphino)-1,1‘binaphthyl]. Inorg. Chem. 2004, 43, 663-673. 
(92) Hashimoto, M.; Igawa, S.; Yashima, M.; Kawata, I.; Hoshino, M.; Osawa, M. Highly Efficient Green Organic Light-Emitting Diodes Containing Luminescent Three-Coordinate Copper(I) Complexes. J. Am. Chem. Soc. 2011, 133, 10348-10351.

(93) Endo, A.; Sato, K.; Yoshimura, K.; Kai, T.; Kawada, A.; Miyazaki, H.; Adachi, C. Efficient up-conversion of triplet excitons into a singlet state and its application for organic light emitting diodes. Appl. Phys. Lett. 2011, 98, 083302.

(94) Hofbeck, T.; Yersin, H. The Triplet State of fac-Ir(ppy)3. Inorg. Chem. 2010, 49, 92909299.

(TOC)

It is shown, how to design a new $\mathrm{Ag}(\mathrm{I})$ complex that exhibits $100 \%$ emission quantum yield at the shortest TADF decay time reported so far. This is a consequence of (i) a small singlet-triplet splitting, (ii) a rigid molecular structure, and most importantly (iii) a very high $\mathrm{S}_{1} \rightarrow \mathrm{S}_{0}$ transition rate.

(Graphical Abstract)

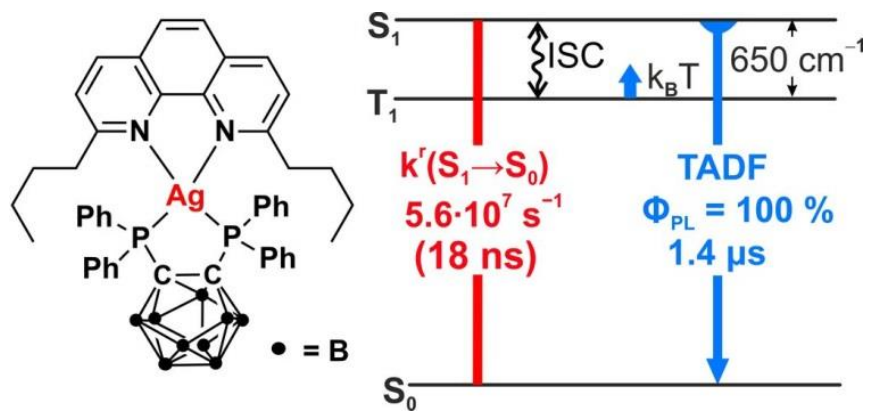




\title{
Design strategy for $\mathbf{A g}(\mathrm{l})$-based thermally activated delayed fluorescence reaching an efficiency breakthrough
}

\author{
Marsel Z. Shafikov ${ }^{\dagger \ddagger}$, Alfiya F. Suleymanova ${ }^{\dagger \S}$, Rafał Czerwieniec ${ }^{\dagger *}$, and Hartmut Yersin ${ }^{\dagger *}$ \\ † Institut für Physikalische und Theoretische Chemie, Universität Regensburg, \\ Universitätsstrasse 31, D-93053 Regensburg, Germany \\ ‡ Ural Federal University, Mira 19, Ekaterinburg, 620002, Russia \\ $\S$ I. Postovsky Institute of Organic Synthesis, Ekaterinburg, 620041, Russia
}

\section{Experimental.}

NMR spectra were recorded on a Bruker AVANCE spectrometer operating at $300 \mathrm{MHz}$ for ${ }^{1} \mathrm{H}$ and $121.5 \mathrm{MHz}$ for ${ }^{31} \mathrm{P}$ with residual protic solvent used as internal standard.

\section{Syntheses}

Bis-(diphenylphosphine)-ortho-carborane. Synthesis was carried out in two steps starting from commercially available ortho-carborane, $n$-butyl-lithium (n-BuLi), and diphenylphosphine chloride. A 1.6 M solution of $\mathrm{n}-\mathrm{BuLi}$ in hexane $(2.9 \mathrm{ml}, 4.68 \mathrm{mmol})$ was added to a solution of ortho-carborane $(0.3 \mathrm{~g}, 2.08 \mathrm{mmol})$ in diethyl ether at $0{ }^{\circ} \mathrm{C}$ and stirred at room temperature for $30 \mathrm{~min}$ and then refluxed for $30 \mathrm{~min}$. The solution was cooled to $0{ }^{\circ} \mathrm{C}$ and diphenylphosphine chloride $(0.95 \mathrm{ml}, 5.2 \mathrm{mmol})$ was added dropwise. The mixture was stirred at room temperature for $30 \mathrm{~min}$ and quenched with a saturated aqueous solution of ammonium chloride. The mixture was extracted with diethyl ether, organic phases were combined, washed with brine, and dried over $\mathrm{MgSO}_{4}$. The solvent removed in vacuo and the residue purified by column chromatography (silica gel, $\left.\mathrm{CH}_{2} \mathrm{Cl}_{2}\right)$ that afforded the product as colorless solid. Yield $55 \%$. ${ }^{1} \mathrm{H} \mathrm{NMR}\left(\mathrm{CDCl}_{3}\right)$ : 7.9-7.79 (m, 8H), 7.50-7.36 (m, 12H), 3.0-1.5 (br, 10H). ${ }^{31} \mathrm{P}$ NMR $\left(\mathrm{CDCl}_{3}\right)$ : $7.82 \mathrm{ppm}$.

$\operatorname{Ag}(\mathbf{d b p})\left(\mathbf{P}_{2}-\mathbf{n C B}\right)$. To a solution of $\mathrm{AgPF}_{6}(0.6 \mathrm{~g}, 2.4 \mathrm{mmol})$ in ethanol bis(diphenylphosphine)-ortho-carborane $(1.2 \mathrm{~g}, 2.4 \mathrm{mmol})$ was added and the mixture was stirred at room temperature for 1 hour. Then 2,9-di- $n$-butyl-1,10-phenanthroline $(0.7 \mathrm{~g}, 2.4 \mathrm{mmol})$ was added and the mixture was refluxed for 1 hour. The solvent was removed in vacuo and the residue was purified by column chromatography (silica gel, $\mathrm{CH}_{2} \mathrm{Cl}_{2}$ ) affording the product as yellow solid. Yield $68.8 \%$. ${ }^{1} \mathrm{H}$ NMR (DMSO-d $\left.{ }_{6}\right): 8.78$ (d, 2H, J = 8.17, Phen.), 8.21 (s, 2H, Phen.), 8.02 (d, 2H, J = 8.60, Phen.), 6.80-7.50 (m, 20H, P(Ph) $)_{2}$, 4.02(m, 2H, n-Bu), 1.51(m, $8 \mathrm{H}, \mathrm{n}-\mathrm{Bu}), 0.75$ (br, 10H, B-H) 0.21(m, 8H, n-Bu). ${ }^{31} \mathrm{P}$ NMR (DMSO-d 6 ): 20.9 ppm. Calculated for $\mathrm{C}_{46} \mathrm{H}_{54} \mathrm{~B}_{9} \mathrm{~N}_{2} \mathrm{P}_{2} \mathrm{Ag}$, \%: C, 61.25; H, 6.03; N, 3.11. Found, \%: C, 60.98; H, 5.97; N, 2.95.

\section{Photophysics}

Photophysical measurements were performed for a powder sample deposited in a helium cryostat (Cryovac Konti Cryostat IT) in which the helium gas flow, gas pressure, and heating were controlled. Thus, the temperature was varied between 1.5 and $300 \mathrm{~K}$. Luminescence spectra were measured with a Horiba Jobin Yvon Fluorolog 3 steady-state fluorescence spectrometer. This spectrometer was modified to allow for measurements of emission decay times. As excitation source a PicoQuant LDH-P-C-375 pulsed diode laser $\left(\lambda_{\mathrm{exc}}=372 \mathrm{~nm}\right.$, pulse 
width $100 \mathrm{ps)}$ was used. The emission signal was detected with a cooled photomultiplier attached to a FAST ComTec multichannel scalar PCI card with a time resolution of 250 ps. Photoluminescence quantum yields were determined with a Hamamatsu C9920-02 system equipped with a Spectralon ${ }^{\circledR}$ integrating sphere.

\section{Calculations.}

M06 ${ }^{1} /$ def2-SVP"3 level of theory with "very tight" criteria was applied for geometry optimizations and M062X ${ }^{1 / d e f 2-S V P}$ level of theory was applied for time-dependent calculations, all using the Gaussian 09D ${ }^{4}$ program.

Table S1. Comparison of selected geometry parameters of $\mathrm{Ag}(\mathrm{dbp})\left(\mathrm{P}_{2}-\mathrm{nCB}\right)$ determined experimentally by an X-ray diffraction study and calculated at the M06/def2-SVP level of theory in the optimized ground state $\left(S_{0}\right)$ and triplet state $\left(T_{1}\right)$ geometries under gas phase conditions. Atom numbering corresponds to the one shown in Figure 1.

Parameters

Ag-N1

Ag-N2

Ag-P1

Ag-P2

N1-Ag-P1

N1-Ag-P2

N2-Ag-P1

N2-Ag-P2

N1-Ag-N2

P1-Ag-P2

C1-N1-Ag-P1

C1-N1-Ag-P2

C2-N2-Ag-P1

C2-N2-Ag-P2
$\mathrm{X}$-ray

Bonds (Å)

$2.3158(18)$

2.36

$2.3207(16)$

2.40

2.49

2.54

2.4770(5)

Angles (degree ${ }^{\circ}$ )

133.87(4)

135

121

132

132.29(4)

119

71

84

85.581(16)

Dihedral angles (degree $\left.{ }^{\circ}\right)$

44.34(18)

50

72.10(16)

66

41.87(19)

47

67.26(17)
2.18

o

$\mathrm{T}_{1}$

2.36

2.44

2.59

155

106

124

113

76

81

30

74

23

72 
Table S2. Electronic transition data resulting from TD-DFT calculations performed in the ground state $\left(\mathrm{S}_{0}\right)$ and the triplet state $\left(\mathrm{T}_{1}\right)$ geometry of $\mathrm{Ag}(\mathrm{dbp})\left(\mathrm{P}_{2}-\mathrm{nCB}\right)$ at the M062X/Def2SVP level of theory.

\begin{tabular}{|c|c|c|c|c|}
\hline \multicolumn{5}{|c|}{ So geometry } \\
\hline State & $\begin{array}{l}\text { Energy } \\
(\mathrm{eV})\end{array}$ & Main contributions & $\begin{array}{l}\text { Oscillator } \\
\text { strength }\end{array}$ & Character \\
\hline $\mathrm{S}_{1}$ & 3.42 & $\begin{array}{l}\text { HOMO } \rightarrow \text { LUMO (51 \%), HOMO-1 } \rightarrow \text { LUMO (43 } \\
\%) .\end{array}$ & 0.0494 & $\begin{array}{c}{ }^{1}\left(\mathrm{ML}_{\mathrm{P} 2-\mathrm{nCB}}\right) \mathrm{L}_{\mathrm{d}} \\
{ }_{\mathrm{bp}} \mathrm{CT}\end{array}$ \\
\hline $\mathrm{S}_{2}$ & 3.57 & $\begin{array}{l}\text { HOMO } \rightarrow \text { LUMO+1 (61 \%), HOMO-1 } \rightarrow \text { LUMO+1 } \\
(33 \%) .\end{array}$ & 0.0063 & $\begin{array}{c}{ }_{b p}^{1}\left(M_{2} C T\right. \\
\end{array}$ \\
\hline $\mathrm{S}_{3}$ & 3.81 & $\begin{array}{l}\text { HOMO-1 } \rightarrow \text { LUMO (49 \%), HOMO } \rightarrow \text { LUMO (43 } \\
\%) .\end{array}$ & 0.0075 & $\begin{array}{c}{ }^{1}\left(\mathrm{MLP}_{\mathrm{bp}} \mathrm{CnCB}\right) \mathrm{Ld}_{\mathrm{d}} \\
\end{array}$ \\
\hline $\mathrm{T}_{1}$ & 3.24 & $\begin{array}{l}\text { HOMO-15 } \rightarrow \text { LUMO (4 \%), HOMO-11 } \rightarrow \\
\text { LUMO+1 (7 \%), HOMO-9 } \rightarrow \text { LUMO (4 \%), } \\
\text { HOMO-15 } \rightarrow \text { LUMO+1 (9\%), HOMO-8 } \rightarrow \text { LUMO } \\
(6 \%), \text { HOMO-8 } \rightarrow \text { LUMO+1 (14 \%), HOMO-6 } \rightarrow \\
\text { LUMO (4 \%), HOMO-6 } \rightarrow \text { LUMO+1 (8 \%), } \\
\text { HOMO-1 } \rightarrow \text { LUMO (14 \%), HOMO-1 } \rightarrow \text { LUMO+1 } \\
(5 \%), \text { HOMO } \rightarrow \text { LUMO (9\%), HOMO-11 } \rightarrow \text { LUMO } \\
(3 \%) .\end{array}$ & 0 & $\begin{array}{c}{ }^{3}\left(\mathrm{ML}_{\mathrm{P} 2-\mathrm{nCB}}\right) \mathrm{L}_{\mathrm{d}} \\
{ }_{\mathrm{bp}} \mathrm{CT}\end{array}$ \\
\hline $\mathrm{T}_{2}$ & 3.33 & $\begin{array}{l}\text { HOMO-1 } \rightarrow \text { LUMO (32 \%), HOMO } \rightarrow \text { LUMO (30 } \\
\%), \text { HOMO-1 } \rightarrow \text { LUMO+1 (9 \%), HOMO } \rightarrow \\
\text { LUMO+1 (6\%). }\end{array}$ & 0 & $\begin{array}{c}{ }^{3}\left(\mathrm{MLP}_{\mathrm{p}-\mathrm{nCB}}\right) \mathrm{L}_{\mathrm{d}} \\
{ }_{\mathrm{bp}} \mathrm{CT}\end{array}$ \\
\hline$T_{3}$ & 3.64 & $\begin{array}{l}\text { HOMO } \rightarrow \text { LUMO (43 \%), HOMO-1 } \rightarrow \text { LUMO+1 } \\
(22 \%), \text { HOMO } \rightarrow \text { LUMO (5 \%), HOMO-8 } \rightarrow \\
\text { LUMO (3\%). }\end{array}$ & 0 & $\begin{array}{c}{ }^{3}\left(\mathrm{MLP}_{\mathrm{P} 2-\mathrm{nCB}}\right) \mathrm{Ld}_{\mathrm{d}} \\
{ }_{\mathrm{bp}} \mathrm{CT}\end{array}$ \\
\hline \multicolumn{5}{|c|}{$T_{1}$ geometry } \\
\hline State & $\begin{array}{c}\text { Energy } \\
(\mathrm{eV})\end{array}$ & Main contributions & $\begin{array}{l}\text { Oscillator } \\
\text { strength }\end{array}$ & Character \\
\hline $\mathrm{S}_{1}$ & 2.36 & $\begin{array}{l}\text { HOMO } \rightarrow \text { LUMO (92 \%), HOMO-1 } \rightarrow \text { LUMO (4 } \\
\%) .\end{array}$ & 0.0536 & $\begin{array}{c}{ }^{1}\left(\mathrm{MLP}_{\mathrm{P}-\mathrm{nCB}}\right) \mathrm{L}_{\mathrm{d}} \\
{ }_{\mathrm{bp}} \mathrm{CT}\end{array}$ \\
\hline $\mathrm{S}_{2}$ & 2.99 & $\begin{array}{l}\text { HOMO } \rightarrow \text { LUMO+1 (95 \%), HOMO-1 } \rightarrow \text { LUMO+1 } \\
\text { (3\%). }\end{array}$ & 0.0066 & $\begin{array}{c}{ }^{1}(\mathrm{MLP2-nCB}) \mathrm{Ld}_{d} \\
{ }_{\mathrm{bp}} \mathrm{CT}\end{array}$ \\
\hline $\mathrm{S}_{3}$ & 3.36 & HOMO $\rightarrow$ LUMO (4 \%), HOMO-1 $\rightarrow$ LUMO (94 \%) & 0.0004 & $\begin{array}{c}{ }^{1}\left(L_{P 2-n C B}\right) L_{d b p} \\
C T\end{array}$ \\
\hline $\mathrm{S}_{4}$ & 3.77 & $\begin{array}{l}\text { HOMO-2 } \rightarrow \text { LUMO (33 \%), HOMO-2 } \rightarrow \text { LUMO } \\
(20 \%), \text { HOMO-17 } \rightarrow \text { LUMO (9 \%), HOMO-9 } \rightarrow \\
\text { LUMO (5 \%), HOMO-5 } \rightarrow \text { LUMO (3 \%). }\end{array}$ & 0.0104 & $\begin{array}{c}{ }^{1}\left(\mathrm{MLP}_{\mathrm{p} 2-\mathrm{nCB}}\right) \mathrm{L}_{d} \\
{ }_{\mathrm{bp}} \mathrm{CT}\end{array}$ \\
\hline $\mathrm{T}_{1}$ & 2.21 & HOMO $\rightarrow$ LUMO (90\%), HOMO-1 $\rightarrow$ LUMO (4\%) & 0 & $\begin{array}{c}{ }^{3}\left(\mathrm{MLP}_{\mathrm{P}-\mathrm{nCB}}\right) \mathrm{L}_{\mathrm{d}} \\
{ }_{\mathrm{bp}} \mathrm{CT}\end{array}$ \\
\hline$T_{2}$ & 2.91 & $\begin{array}{l}\text { HOMO } \rightarrow \text { LUMO+1 (79 \%), HOMO-1 } \rightarrow \text { LUMO+1 } \\
(3 \%), \text { HOMO-9 } \rightarrow \text { LUMO+1 (2 \%). }\end{array}$ & 0 & $\begin{array}{c}{ }^{3}(\mathrm{MLp2-nCB}) \mathrm{Ld}_{d} \\
{ }_{\mathrm{bp} C T}\end{array}$ \\
\hline$T_{3}$ & 3.17 & $\begin{array}{l}\text { HOMO } \rightarrow \text { LUMO+1 (10 \%), HOMO-7 } \rightarrow \text { LUMO } \\
(6 \%), \text { HOMO-8 } \rightarrow \text { LUMO (5 \%), HOMO-9 } \rightarrow \\
\text { LUMO+1 (7 \%), HOMO-9 } \rightarrow \text { LUMO (17 \%), }\end{array}$ & 0 & 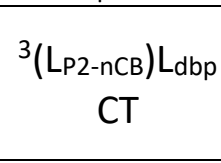 \\
\hline
\end{tabular}




\begin{tabular}{|l|l|l|l|}
\hline & $\begin{array}{l}\text { HOMO-10 } \rightarrow \text { LUMO (3 \%), HOMO-15 } \rightarrow \text { LUMO } \\
(14 \%), \text { HOMO-11 } \rightarrow \text { LUMO (6 \%). }\end{array}$ & & \\
\hline
\end{tabular}

Table S3. Orbital energies and characters resulting from Mulliken population analysis calculated for $\mathrm{Ag}(\mathrm{dbp})\left(\mathrm{P}_{2}-\mathrm{nCB}\right)$ at the M062X/def2-SVP level of theory for the ground-state $\left(S_{0}\right)$ and lowest triplet state $\left(T_{1}\right)$ optimized geometries.

\begin{tabular}{|c|c|c|c|c|c|c|}
\hline \multicolumn{7}{|c|}{ So state geometry } \\
\hline \multirow[t]{2}{*}{ Orbital } & \multirow{2}{*}{$\begin{array}{c}\text { Energy, } \\
\text { (eV) }\end{array}$} & \multicolumn{5}{|c|}{ Contributions, (\%) } \\
\hline & & dbp. ${ }^{a}$ & $\mathrm{Ag}$ & $\mathbf{P}$ & Ph. ${ }^{b}$ & $\mathrm{nCB}^{\mathrm{c}}$ \\
\hline LUMO+4 & 0.09 & 3 & 1 & 7 & 87 & 2 \\
\hline LUMO+3 & -0.14 & 10 & 7 & 11 & 69 & 3 \\
\hline LUMO+2 & -0.37 & 84 & 4 & 1 & 7 & 0 \\
\hline LUMO+1 & -1.60 & 91 & 0 & 0 & 0 & 0 \\
\hline LUMO & -1.71 & 93 & 1 & 0 & 0 & 0 \\
\hline HOMO & -6.43 & 1 & 3 & 10 & 6 & 72 \\
\hline HOMO-1 & -6.80 & 2 & 12 & 43 & 20 & 21 \\
\hline HOMO-2 & -7.75 & 2 & 6 & 19 & 32 & 38 \\
\hline HOMO-3 & -7.97 & 1 & 1 & 2 & 27 & 67 \\
\hline HOMO-4 & -8.07 & 0 & 0 & 1 & 40 & 55 \\
\hline \multicolumn{7}{|c|}{$T_{1}$ state geometry } \\
\hline \multirow[t]{2}{*}{ Orbital } & Energy, & \multicolumn{5}{|c|}{ Contributions, (\%) } \\
\hline & $(\mathrm{eV})$ & $d b p^{a}$ & $\mathrm{Ag}$ & $\mathbf{P}$ & Ph. ${ }^{b}$ & $\mathrm{nCB}^{\mathrm{c}}$ \\
\hline LUMO+4 & 0.04 & 3 & 2 & 9 & 84 & 2 \\
\hline LUMO+3 & -0.16 & 4 & 4 & 9 & 81 & 3 \\
\hline LUMO+2 & -0.35 & 87 & 4 & 1 & 5 & 0 \\
\hline LUMO+1 & -1.61 & 92 & 0 & 0 & 0 & 0 \\
\hline LUMO & -2.09 & 90 & 1 & 1 & 1 & 0 \\
\hline HOMO & -6.09 & 3 & 13 & 47 & 18 & 16 \\
\hline HOMO-1 & -6.60 & 1 & 2 & 8 & 5 & 76 \\
\hline HOMO-2 & -7.65 & 2 & 10 & 23 & 33 & 28 \\
\hline HOMO-3 & -8.02 & 1 & 0 & 1 & 42 & 54 \\
\hline HOMO-4 & -8.12 & 1 & 1 & 1 & 34 & 59 \\
\hline \multicolumn{7}{|c|}{$\begin{array}{l}\text { a) di- } n \text {-butyl-phenanthroline ligand (dbp) } \\
\text { b) phenyl groups of } \mathrm{P}_{2} \text {-nCB ligand } \\
\text { c) nido-carboranyl moiety of } \mathrm{P}_{2} \text {-nCB ligand }\end{array}$} \\
\hline
\end{tabular}


Table S4. Iso-surface contour plots (iso-value 0.05) and energies of the molecular orbitals relevant for the lowest excited states of $A g(d b p)\left(P_{2}-n C B\right)$ as calculated at the M062X/def2SVP theory level in the ground state $\left(S_{0}\right)$ geometry.
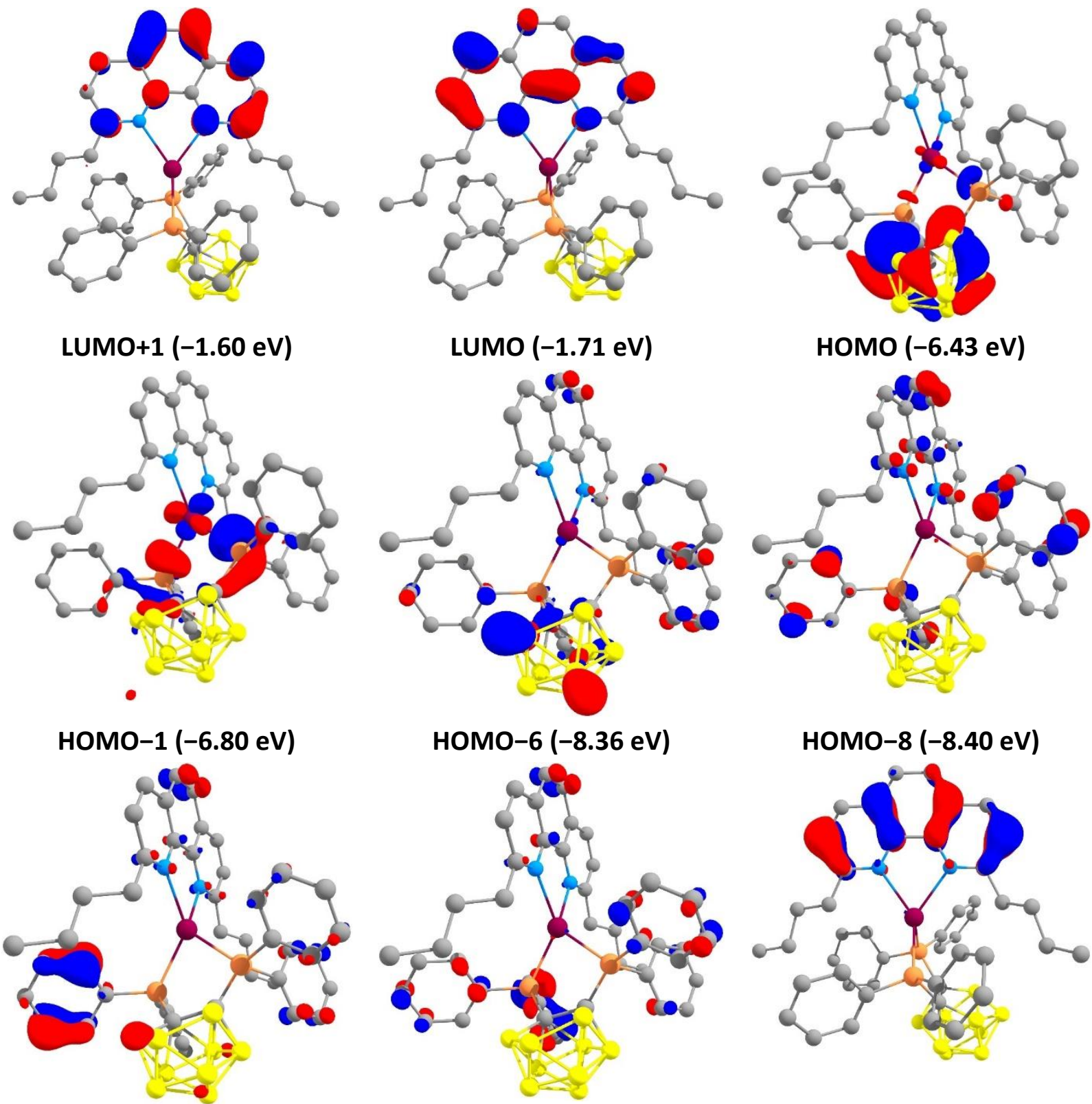

HOMO-9 (-8.42 eV)

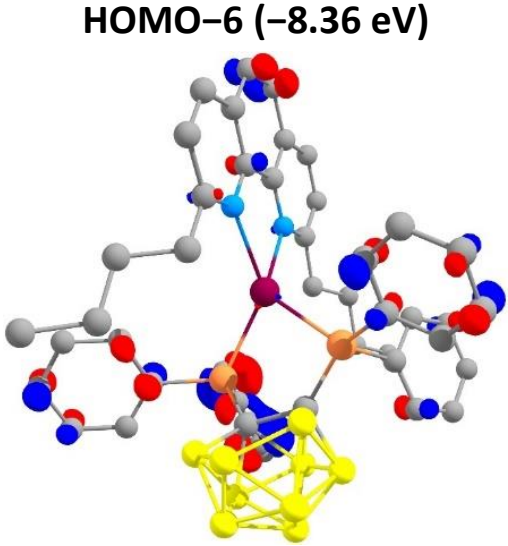

HOMO-11 (-8.55 eV)

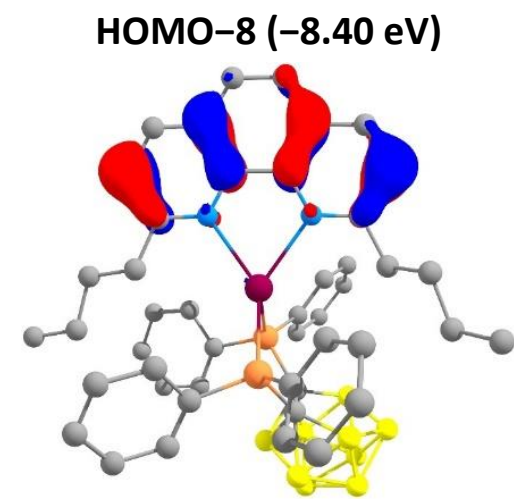

HOMO-15 (-8.86 eV) 
Table S5. Iso-surface contour plots (iso-value 0.05) and energies of the molecular orbital relevant to the lowest excited states of $\mathrm{Ag}(\mathrm{dbp})\left(\mathrm{P}_{2}-\mathrm{nCB}\right)$ as calculated at the M062X/def2-SVP theory level in the lowest triplet-state $\left(T_{1}\right)$ geometry.
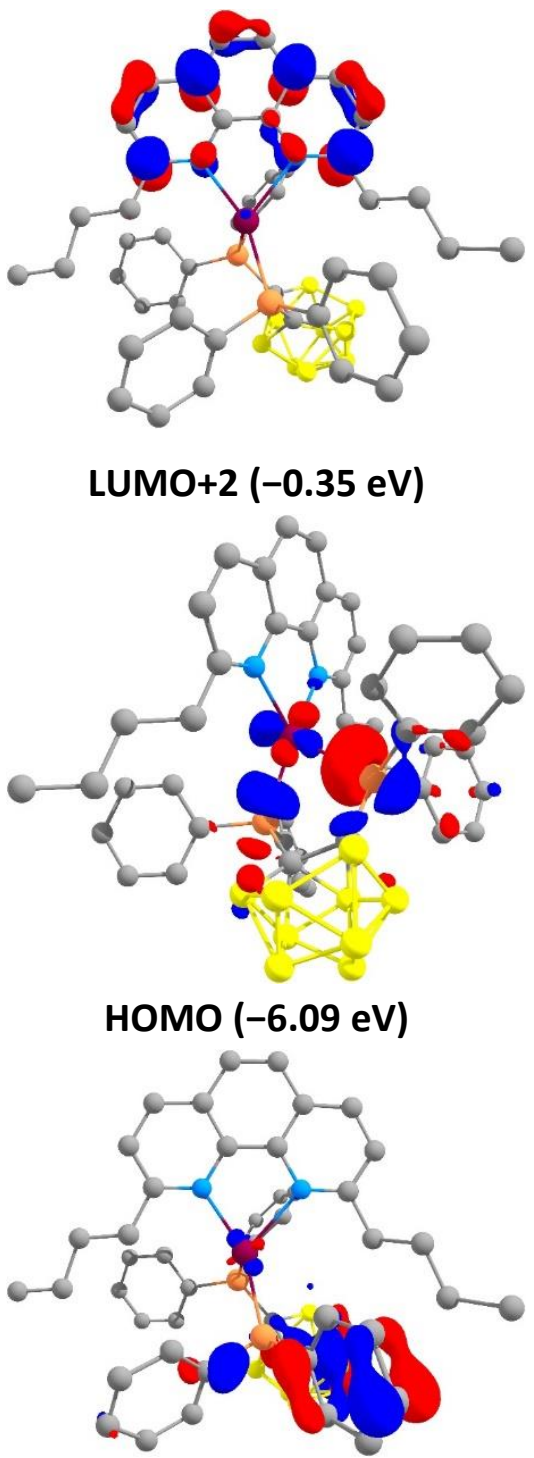

HOMO-5 (-8.28 eV)
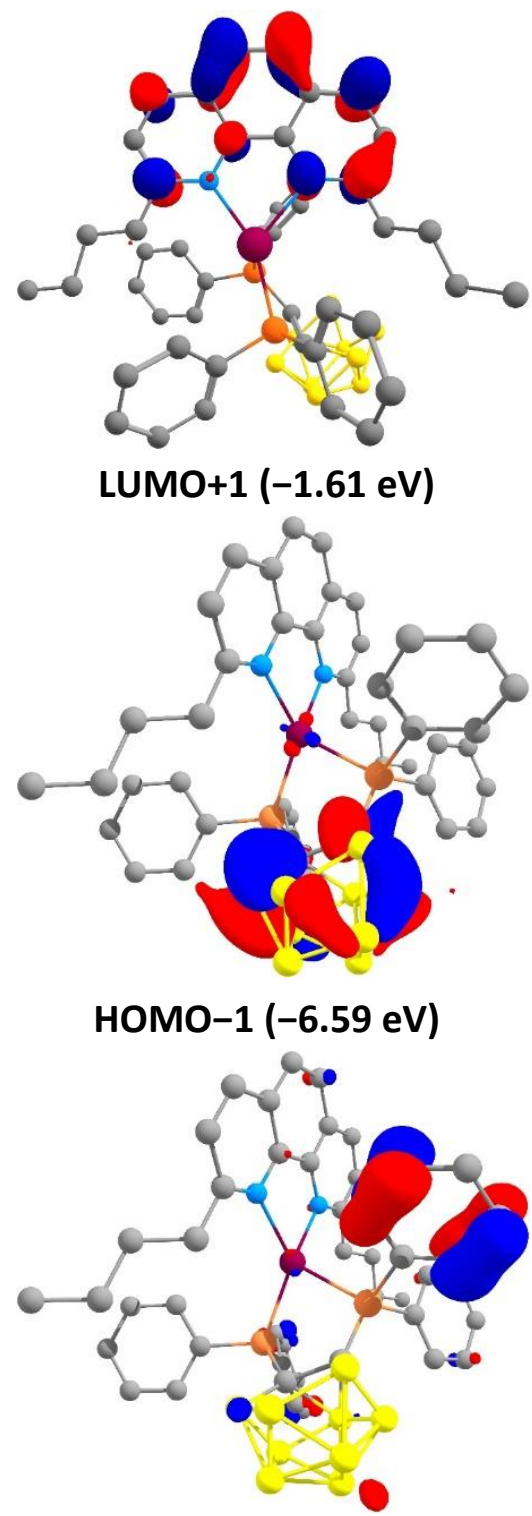

HOMO-7 (-8.37 eV)
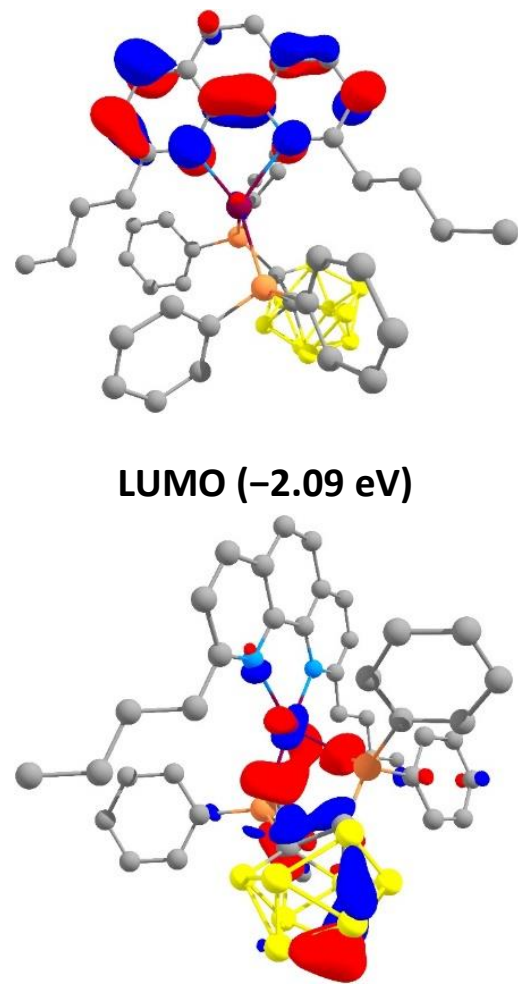

HOMO-2 (-7.65 eV)

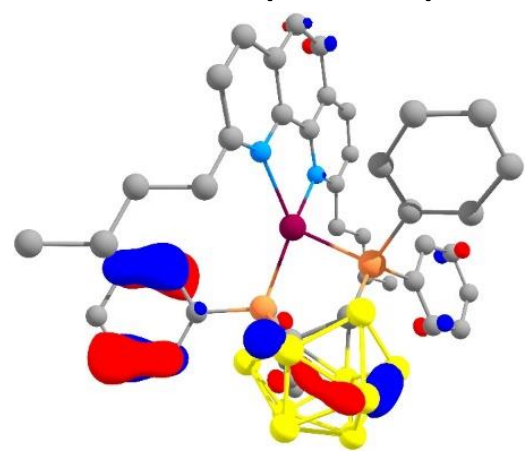

HOMO-8 $(-8.44 \mathrm{eV})$ 

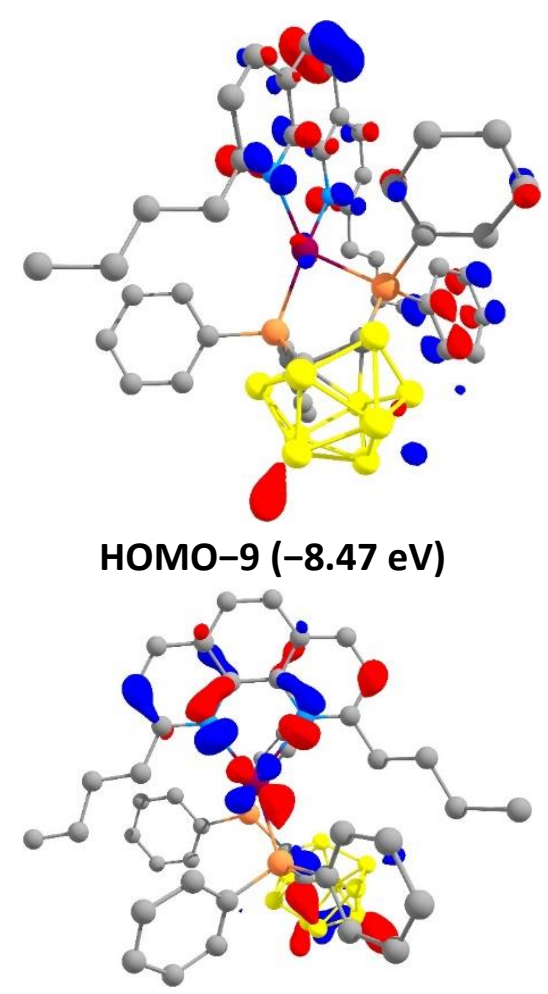

HOMO-14 (-8.79 eV)
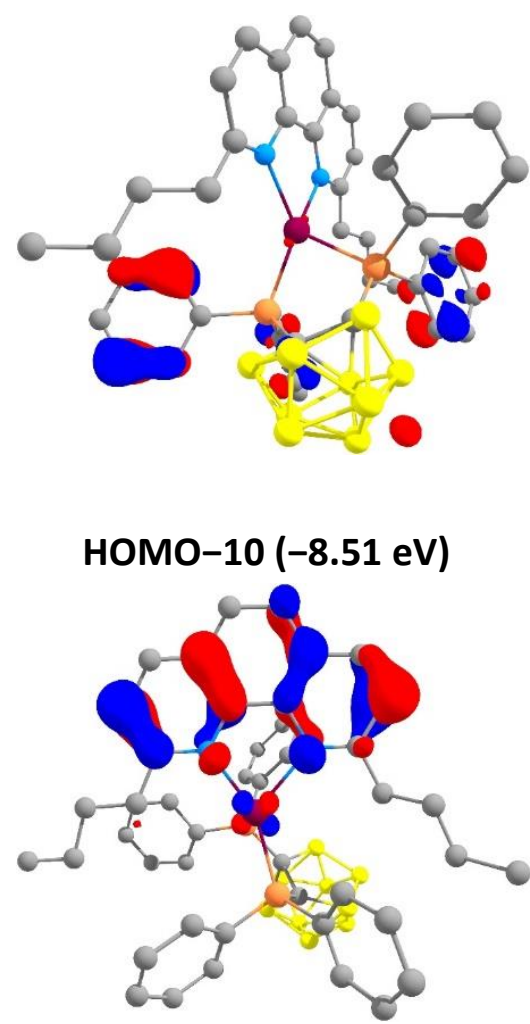

HOMO-15 (-8.84 eV)
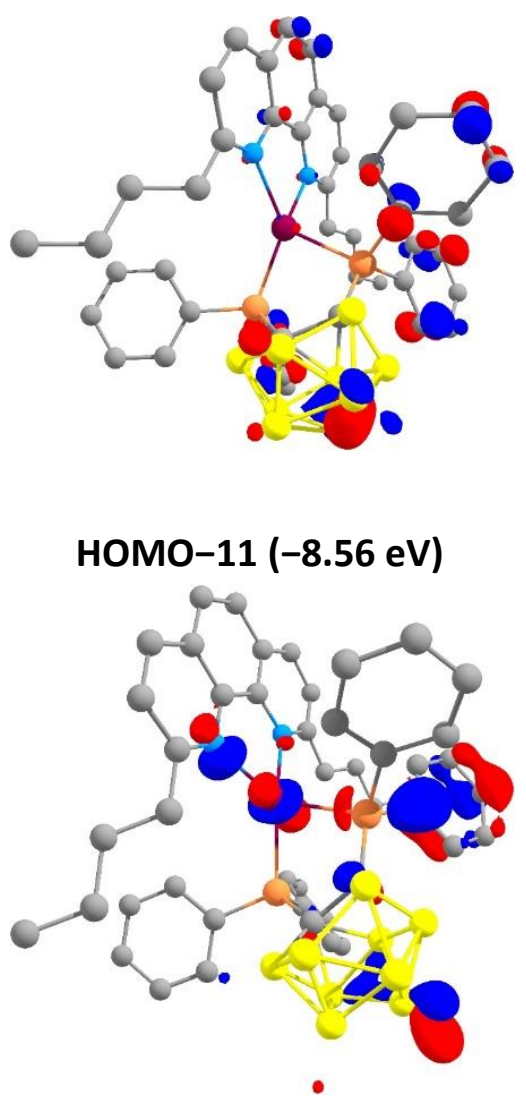

HOMO-17 (-9.00 eV)

\section{References}

(1) Zhao, Y.; Truhlar, D. G. The M06 suite of density functionals for main group thermochemistry, thermochemical kinetics, noncovalent interactions, excited states, and transition elements: two new functionals and systematic testing of four M06-class functionals and 12 other functionals. Theor. Chem. Acc. 2007, 120, 215-241.

(2) Weigend, F.; Ahlrichs, R. Balanced basis sets of split valence, triple zeta valence and quadruple zeta valence quality for H to Rn: Design and assessment of accuracy. Phys. Chem. Chem. Phys. 2005, 7, 3297-3305.

(3) Weigend, F. Accurate Coulomb-fitting basis sets for H to Rn. Phys. Chem. Chem. Phys. 2006, $8,1057-1065$.

(4) Frisch, M. J.; Trucks, G. W.; Schlegel, H. B.; Scuseria, G. E.; Robb, M. A.; Cheeseman, J. R.; Scalmani, G.; Barone, V.; Mennucci, B.; Petersson, G. A.; Nakatsuji, H.; Caricato, M.; Li, X.; Hratchian, H. P.; Izmaylov, A. F.; Bloino, J.; Zheng, G.; Sonnenberg, J. L.; Hada, M.; Ehara, M.; Toyota, K.; Fukuda, R.; Hasegawa, J.; Ishida, M.; Nakajima, T.; Honda, Y.; Kitao, O.; Nakai, H.; Vreven, T.; Montgomery Jr., J. A.; Peralta, J. E.; Ogliaro, F.; Bearpark, M. J.; Heyd, J.; Brothers, E. N.; Kudin, K. N.; Staroverov, V. N.; Kobayashi, R.; Normand, J.; Raghavachari, K.; Rendell, A. P.; Burant, J. C.; Iyengar, S. S.; Tomasi, J.; Cossi, M.; Rega, N.; Millam, N. J.; Klene, M.; Knox, J. E.; Cross, J. B.; Bakken, V.; Adamo, C.; Jaramillo, J.; Gomperts, R.; 
Stratmann, R. E.; Yazyev, O.; Austin, A. J.; Cammi, R.; Pomelli, C.; Ochterski, J. W.; Martin, R. L.; Morokuma, K.; Zakrzewski, V. G.; Voth, G. A.; Salvador, P.; Dannenberg, J. J.;

Dapprich, S.; Daniels, A. D.; Farkas, Ö.; Foresman, J. B.; Ortiz, J. V.; Cioslowski, J.; Fox, D. J. Gaussian 09, Gaussian, Inc.: Wallingford, CT, USA, 2009. 